\title{
Research
}

\section{Participatory Simulation of Land-Use Changes in the Northern Mountains of Vietnam: the Combined Use of an Agent-Based Model, a Role-Playing Game, and a Geographic Information System}

\author{
$\underline{\text { Jean-Christophe Castella }}^{1}, \underline{\text { Tran Ngoc Trung }}^{2}$, and Stanislas Boissau $^{3}$
}

\begin{abstract}
In Vietnam, the remarkable economic growth that resulted from the doi moi (renovation) reforms was based largely on the rural households that had become the new basic unit of agricultural production in the early 1990s. The technical, economic, and social changes that accompanied the decollectivization process transformed agricultural production, resource management, land use, and the institutions that defined access to resources and their distribution. Combined with the extreme biophysical, technical, and social heterogeneity encountered in the northern mountains, these rapid changes led to the extreme complexity of the agrarian dynamics that today challenges traditional diagnostic approaches. Since 1999, a participatory simulation method has been developed to disentangle the cause-and-effect relationships between the different driving forces and changes in land use observed at different scales. Several tools were combined to understand the interactions between human and natural systems, including a narrative conceptual model, an agent-based spatial computational model (ABM), a role-playing game, and a multiscale geographic information system (GIS). We synthesized into an ABM named SAMBA-GIS the knowledge generated from the above tools applied to a representative sample of research sites. The model takes explicitly into account the dynamic interactions among: (1) farmers' strategies, i.e., the individual decision-making process as a function of the farm's resource profile; (2) the institutions that define resource access and usage; and (3) changes in the biophysical and socioeconomic environment. The next step consisted of coupling the ABM with the GIS to extrapolate the application of local management rules to a whole landscape. Simulations are initialized using the layers of the GIS, e.g., land use in 1990, accessibility, soil characteristics, etc., and statistics available at the village level, e.g., population, ethnicity, livestock, etc. At each annual time step, the agrarian landscape changes according to the decisions made by agent-farmers about how to allocate resources such as labor force, capital, and land to different productive activities, e.g., crops, livestock, gathering of forest products, off-farm activities. The participatory simulations based on SAMBA-GIS helped identify villages with similar land-use change trajectories to which the same types of technical and/or institutional innovations could be applied. Scenarios of land-use changes were developed with local stakeholders to assess the potential impact of these changes on the natural resource base and on agricultural development. This adaptive approach was gradually refined through interactions between researchers and the local population.
\end{abstract}

Key Words: participatory simulation; agent-based model; role-playing game; geographic information systems; land-use change; mountain agriculture; Vietnam 


\section{INTRODUCTION: FROM DEVELOPMENT ISSUES TO METHODOLOGICAL CHALLENGES}

\section{Coping with rapid institutional changes in a complex human ecological environment}

Known as doi moi or renovation, the economic reforms of 1986, which included market liberalization and decentralization policies, have dramatically transformed Vietnam. Within a decade, the process of decollectivization changed agriculture from centrally planned production managed by large-scale cooperatives into familybased agriculture made up of a multitude of production units managing small plots of land. Major land policies succeeded one another at a rapid pace. In 1981, paddylands were distributed to individual households under Decree 100, marking the beginning of the decollectivization process. Then Resolution 10 (April 1988) defined the main modalities of the allocation of paddyland, with the 1993 land law providing additional details on the allocation of forest land. All means of production gradually returned to individuals. These very rapid changes obliged farmers and, more generally, all the actors in the agricultural sector to adopt an adaptive mode of management of agricultural production and natural resources (Kerkvliet and Porter 1995). They were caught up in a process of social learning imposed by the rapid transformations of their institutional and socioeconomic environment (Dao 1995). Research covering this transitional period showed that short-term individual strategies often prevailed and that the actors paid little attention to the sustainability of the resource base (Jamieson et al. 1998). The lack of control by policy makers over the local management of natural resources resulted in large-scale deforestation in the 1980s. Finally, the 1993 land law did manage to bring the spiral of environmental degradation under control (Castella and Dang 2002). Within a period of only a few years, a new form of organization of the agricultural sector emerged from the complex interactions that existed among the different groups of stakeholders.

In the northern mountainous regions, these development trends were expressed in many different ways, depending on local circumstances (Dao and Jésus 1995). The ethnic composition of communities, soil types, land-use patterns, etc., differ substantially from one valley to the other, which creates a very complex picture in which nothing can be classified as a typical district, village, or even household (Rambo 1997). The changes that accompanied agricultural decollectivization against a background of complex human ecological mosaics led to a rapid differentiation in farming-system strategies and land-use patterns that was completely different from the relatively homogeneous rules that had prevailed under the cooperative system. This emerging complexity challenges classic methods of land-use analysis and planning, and calls for innovative approaches to understanding changes in land use and the impact of these changes on the environment.

\section{The need for integration of interdisciplinary knowledge across scales}

The difficulty of working within the extreme diversity of the mountainous regions is exacerbated by the lack of empirical data on these areas. Further, the data that are available are often fragmented or pieced together from geographically limited case studies. Monographs are a tool that is widely used by social scientists to investigate the way that farmers manage their land-use systems at the local level, i.e., from field and farm to household and village community, and to put them into a historical perspective (Mazoyer and Roudart 1997). Researchers typically spend long periods living and interacting with local populations. Their empirical knowledge is usually delivered as narratives that reconstruct and interpret land-use trajectories based on comparative analysis of individual story lines, farm typologies (Landais 1998), and interactions between farm households and among other stakeholders in social networks (Steins and Edwards 1999, Ravnborg and Westermann 2002). Such case studies were an essential component of Farming Systems Research during the 1980s (Conway 1985, Collinson 2000) and are still important today to anchor the diagnostic phase of a project in a rich empirical foundation (Evans and Kelley 2004).

Between 1998 and 2000, six case studies were implemented in the province of Bac Kan in northern Vietnam by the Mountain Agrarian Systems Program, a joint research project of the Vietnam Agricultural Science Institute, the Institut de Recherche pour le Développement, the Centre de Coopération Internationale en Recherche Agronomique pour le Développement, and the International Rice Research Institute (for more information see http://www.knowledgebank.irri.org/sam/home en. 
html). The synthesis of empirical knowledge from direct inquiries, secondary data, and analysis of chronological series of aerial photographs resulted in a comprehensive understanding of local development issues, with particular emphasis on the social management of natural resources (Castella and Dang 2002). However, the recommendations generated from these case studies were difficult to extrapolate over large areas, especially in such a heterogeneous environment. The large number of replications that would be needed to extrapolate the results to regional scales was limited by the human and financial means that were available as well as by time constraints (Sayer and Campbell 2004). A comparative analysis of the available case studies attempted to decontextualize the main drivers of change in land use. Those with a marked impact at the regional level were discriminated from the locality-specific artifacts (Castella et al. 2005). For example, the distribution of lowland fields to individual households was identified as a major driving factor of the rapid and massive deforestation of the hillsides in the 1980s. Converging results from highly contrasted natural and human environments were represented as a conceptual model of the agrarian transition between cooperative and household-based agriculture. First expressed as a narrative, this model described changes in farming practices and strategic decisions as a function of the demographic composition of the household and access to irrigated lowland for paddy cultivation (Castella and Dang 2002).

An agent-based model (ABM) was then developed to assess the impact of the individual decisions and actions of farmers/agents on the observed changes in the landscape and the environment (Parker et al. 2003, Bousquet and Le Page 2004). The computational model known as SAMBA was developed under the Cormas simulation platform (Bousquet et al. 1998). The model's name is formed from "SAM," the French acronym for mountain agrarian systems and the name of the project in which the methodology was developed, and $b a$, which means "three" in Vietnamese. The model is considered a link between two components of the project; the first deals with identifying land-use changes and the problems that are a priority with local stakeholders, and the second involves intervention through the design and testing of technical and organizational innovations, in collaboration with farmers. SAMBA satisfactorily simulated changing farmers' practices in the 1980s and helped establish the causal relationship between a policy related to land tenure in the lowlands and the massive deforestation trend on the hillsides (Castella et al. 2005).

\section{Toward a spatial agent-based model for participatory simulation of land-use changes}

Alhough the explanatory quality of this first model was derived from its simplicity, it was in fact too simple to capture the complexity of the changes that occurred after 1993, when a second round of land reforms allocated the forest land to individual households in an attempt to stop runaway deforestation and environmental degradation. This new policy, combined with economic liberalization and the development of ambitious government projects for the alleviation of poverty and for reforestation in the mountains, accelerated the process of agricultural transformation. A new model incorporating ongoing processes had to be developed to keep up with the rapid pace of change. However, the development of such a model was challenging for the very reasons that we needed a model: the more complex reality and the rapid pace of the changes. In such complex institutional and natural environments, participatory modeling can contribute to data acquisition and analysis across multiple scales and to the integration of interdisciplinary knowledge (Bousquet et al. 2002, Walker et al. 2002). Furthermore, the active participation of stakeholders is crucial for integrating multiple perspectives with regard to the use of natural resources and for disentangling the cause-and-effect relationships among different driving forces and changes in land use observed at different scales (Leeuwis 2000, Johnson et al. 2003).

An agent-based model of land use/cover change (ABM-LUCC) is an effective tool for exploring agent diversity and landscape heterogeneity within a spatially explicit structure (Evans and Kelley 2004). There is a wide range of possible applications from theoretical abstract models to more realistic applied models designed to aid problem solving and to provide support for land-use planning and policy formulation. The former can help test candidate explanations for empirically observed phenomena, i.e., explanatory models, whereas the latter attempt to mimic real-world systems to predict their future transformation or to explore scenarios, i.e., descriptive, exploratory models, (Parker et al. 2003). To make them more realistic, the descriptive models for LUCC can be coupled with GIS (Parker 
2005). In addition, role-playing games (RPG) can help elicit stakeholders' representations. The rules that govern the decisions made by individual agents are then incorporated into the model by observing the behavior of the players (Bousquet et al. 2002, Barreteau 2003).

This paper investigates the synergies between ABM, RPG, and GIS methods once they are combined and applied to complex, real-world development issues. The next section introduces the action-research framework developed and tested in Bac Kan province to overcome the methodological problems inherent in the northern mountains of Vietnam, which included the capture of local knowledge in a rapidly changing institutional environment and the issue of representativeness in the selection of study sites and of participants in participatory simulations. We then present the participatory modeling approach as an iterative process throughout the different stages of field work, modeling, role playing, and building platforms for interactions between stakeholders about the management of natural resources. RPG and $A B M$ are used in combination to understand local mechanisms of land change with particular emphasis on human-induced drivers. Finally, the contextual knowledge generated through the local communication platforms is extrapolated to a regional landscape by coupling the spatially explicit $\mathrm{ABM}$ with a GIS. The resulting ABM-LUCC, named SAMBA-GIS, facilitates the process of participatory simulation, which in return consolidates the model by adding new rules or by calibrating its parameters. These rules and parameters are both the core of the model and at the same time the drivers and mechanisms of land change that are investigated with the model. Consequently, the SAMBA-GIS model is presented in this paper both as a process for the development of a methodology and the result of its application in the context of Bac Kan province.

\section{PRESENTATION OF THE STUDY AREA AND RESEARCH FRAMEWORK}

\section{A heterogeneous natural and human environment}

Bac Kan is a mountainous province located $150 \mathrm{~km}$ north of Hanoi (Fig. 1). In the absence of industrial and commercial activities, the farmers of Bac Kan depend to a large extent on subsistence agriculture.
Most of the subsistence agriculture in Bac Kan Province is based on the cultivation of paddy rice in the limited valley bottoms that cover only $2.6 \%$ of the province. Other important subsistence crops include maize $(21,000$ ha in 2000) and cassava (26,700 ha), which are mainly used for feeding pigs and are not traded commercially. Cash crops include soybean (1080 ha), sugarcane (460 ha), peanuts (400 ha), and tobacco (175 ha). Although cash crops are not grown on much of the land in the province, they may nevertheless account for a large proportion of farmers' incomes. In addition, the raising of large ruminants such as cows and buffaloes has remained stable or decreased over the past few years because livestock put pressure on natural resources and are also a major source of conflict associated with crop damage and the use of resources (Castella and Dang 2002). Finally, perennial plantations of fruit and timber have developed rapidly in recent years, helped along by projects that have included training and subsidies for tree growers. Five major ethnic groups live in Bac Kan Province: the Tay $(55 \%)$, the Dao $(17 \%)$, the Kinh or Viet $(13 \%)$, the Nung $(9 \%)$, and the H'mong $(5 \%)$. The population is divided into two major groups. The first group, composed of the Tay, Nung, and Kinh, includes the majority of the population in the province. These people live along the major channels of communication and transportation close to population centers such as Bac Kan town and the district administrative centers. They control most of the political and administrative institutions in the province. Their settlements are close to rivers and streams, and they predominantly engage in paddy rice cultivation. Helped by good accessibility and market integration, they sell much of their agricultural production. The rest of the population of Bac Kan Province, i.e., the Dao and H'mong, lives in remote areas that are difficult to access. They have limited areas of irrigable flatland suitable for paddy rice. Instead, these people often rely on extensive hillside slash-and-burn cultivation systems, the yields of which are very vulnerable to climatic variability. Agricultural production is mostly for household consumption. Although many of these ethnic groups were nomadic peoples in the past, most switched to sedentary production systems after the allocation of forest land.

This province is one of the major focal areas of the Ministry of Agriculture and Rural Development because of growing population pressure, the large number of farmers who still practice shifting cultivation, and the already substantial deterioration 
Fig. 1. Map of Bac Kan Province showing the research sites.

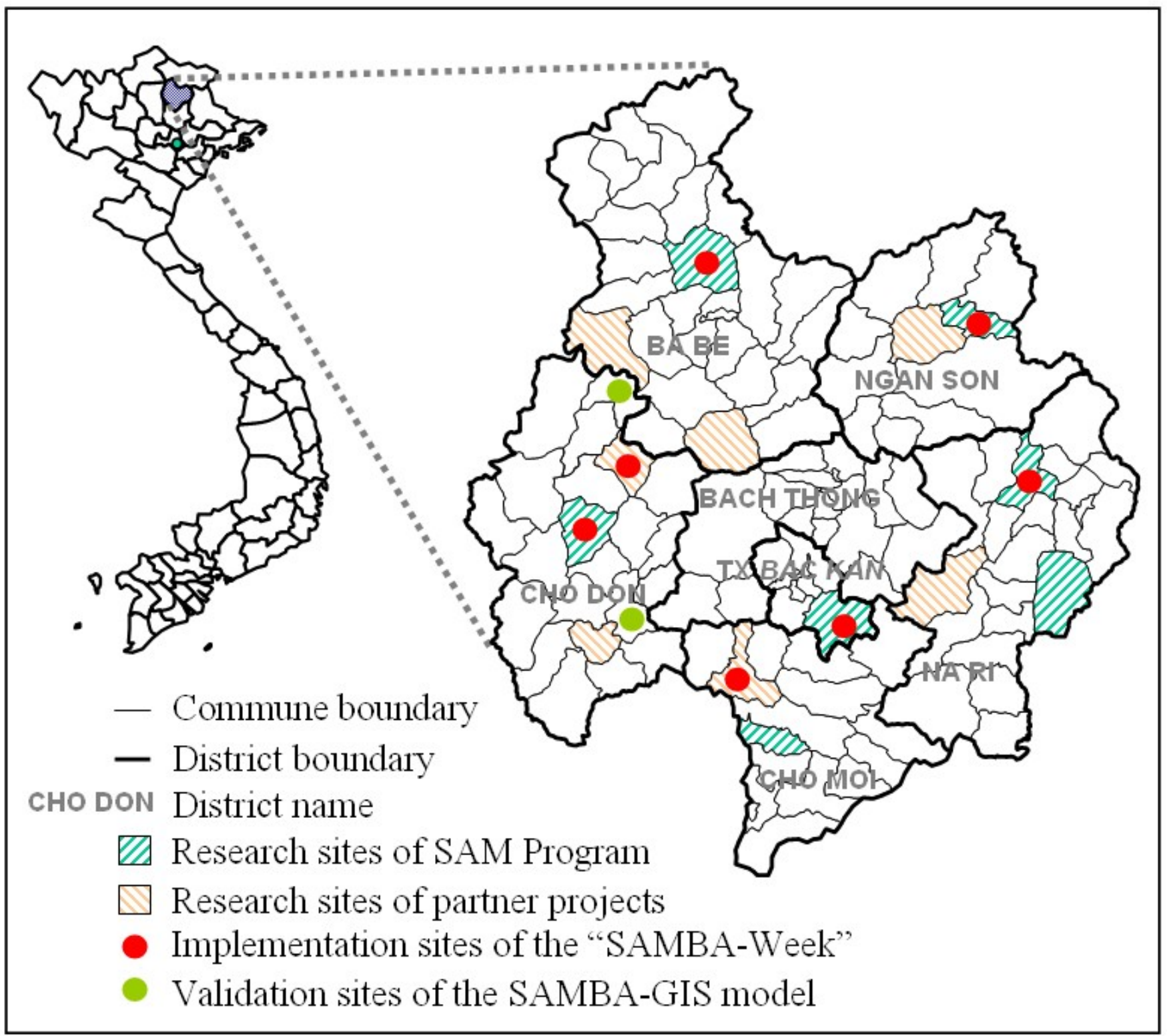

of the natural resource base. It was expected that local populations and authorities would be easily mobilized around these burning environmental issues (Castella et al. 2004). The synchronic and diachronic aspects of the study both played a role in selecting study sites within the province (Fig. 1). The diachronic analysis required sites for which sufficient historical data were available, including chronological series of remote sensing data, whereas the synchronic analysis necessitated that the study sites be selected in terms of their current stage in an evolutionary process that involves market integration, infrastructure, rural exodus, etc. To satisfy both of these requirements, the research sites for the monographic studies were selected to cover the regional diversity along each of these axes: 
agro-ecological diversity and the full gradient of market integration (Castella and Dang 2002).

\section{History of the agrarian system}

The monographic studies conducted in Bac Kan province made it possible for us to compile the following history of the agrarian system during the 20 th century. This history can be summarized as a succession of four different kinds of land use (Castella and Dang 2002).

1. Before agricultural collectivization at the end of the 1950s, land use was relatively extensive, with a single rice crop per year in the lowlands and slash-and-burn agriculture with long fallow periods in the uplands. The Tay occupied the lowlands, and the Dao lived in the uplands.

2. During the collective period (1960-1988), lowland rice production was intensified using the technologies of the Green Revolution. The Dao people were moved to the valley bottoms to contribute to the newly founded cooperatives alongside Tay households. Cultivation of the hillsides was forbidden by local regulations, and the practice of slash and burn was restricted to a few small fields near the village.

3. In the late 1970 s and early 1980 s, agricultural production was unable to keep pace with the growing population of the region, whereas the hillsides continued to be underexploited. Although the resource base was maintained, the food needs of people were not being met. Beginning in 1982, a series of reforms led to the eventual dissolution of the cooperative system. This failure culminated in an abrupt return to traditional shifting cultivation practices and an uncontrolled rush to clear and appropriate as much upland area as possible. Within a few years most of the forests in the province had been cleared.

4. In 1990, there was a spontaneous movement among the Tay to reclaim the paddy fields that had been collectivized in 1960. Families took back the paddy fields of their ancestors, reproducing the land inequalities of the preindependence system. The households who could secure individual ownership, first of paddy fields and then of sloping lands, intensified paddyland production by means of techniques such as rice double-cropping, chemical fertilizers, and mechanization, and then increased both their labor investment as well as their medium- and long-term investment on the hillsides, e.g., permanent agro-forestry systems, expansion of land under maize associated with pig raising, and perennial plantations. However, not all families were able to develop such sustainable land uses. Families who had joined the cooperatives in the later years of collectivization, mainly Dao ethnics, were deprived of the paddy fields on which they had been working for years, and many subsequently had no other choice but swidden cultivation. These families are now facing a critical situation of poverty, whereas, for the dominant Tay villages, agriculture has generally improved over the past decade from both an agro-ecological and a socioeconomic point of view.

\section{Selection of sites and participants}

Throughout the 1990s, farmers' strategies evolved based on their access to land ownership and to the other means of production available to them. Given the complexity and the rapid pace of these recent agricultural changes, it was not possible to use the same tools as those used to describe the deforestation trend of the 1980s (Castella et al. 2005). A scientist-driven model based on an abstract hypothetical landscape could not adequately simulate farmers' decisions in context (Castella et al. 2003). Building on previous work (Barreteau and Bousquet 2001, Barreteau 2003), the SAMBA agent-based model was transformed into a roleplaying game (RPG). As with the computational model, two hierarchical levels were taken into account in the RPG: the household level and a higher level of landscape observation. The farm household was the relevant unit for characterizing and analyzing the individual decision-making process, whereas the consequences of these decisions on land use were observed at the village scale. The village was selected as the landscape modeling unit because it is a coherent entity for the management of natural resources from both a biophysical and a sociological point of view. In the mountainous regions of 
northern Vietnam, the village territory usually corresponds to a small watershed with a tiered spatial organization of land uses, and the village community is the basic social system that collectively manages the local resources (Castella and Dang 2002). The strong social cohesion between villagers and the intensity of interactions within the village community as compared to higher administrative entities such as the commune, district, or province was also considered to be an important factor in the success of the grass-roots level communication platform on natural resources management (Ravnborg and del Pilar Guerrero 1999). Consequently, the complex system under scrutiny was the village agro-ecosystem whose biophysical boundaries matched the social boundaries of the village community. One or two villages were selected at each study site or commune in which the monographic studies had previously been conducted (Fig. 1). As mentioned above, these sites had been selected to cover two ranges of diversity, agro-ecological and integration to market. Within each site, the villages represented the contrasting cultivation practices of paddy rice in the lowland and swidden agriculture on the hillsides, which also corresponded to the main ethnic groups present in the area. When both groups were not present in one village, two villages were selected. About 10 farmers were invited to participate as players. They were selected according to the following criteria: age, gender, ethnicity, wealth, social position in the community, and farm management strategies based on the results of monograph studies that had previously been conducted at the same site. Again, the objective was to maximize the diversity of situations.

\section{ACQUIRING KNOWLEDGE ABOUT LOCAL PROCESSES OF LAND CHANGE THROUGH PARTICIPATORY SIMULATION}

\section{The sequence of the participatory simulation}

We called this approach "SAMBA-Week" because it was extended to five-day sessions (Boissau and Castella 2003). "SAM" is the French acronym for "mountainous agrarian system," and $b a$ is the Vienamese word for "three." The first day was dedicated to the role-playing game (RPG). The grid of the simulation environment was represented by a game board composed of cubes with each side painted a different color; each color represented a type of land use or cover (Fig. 2). With the help of the facilitators, the participants designed a virtual landscape resembling their own village on the game board. They drew cards that accounted for the composition of their virtual families and the numbers of paddy fields and buffalos they owned in the game. They then had to manage their production to feed their families. Through these actions, the farmers were able to change the land use and the land cover represented by the different colors on the game board (Fig. 2). For an individual action, such as opening upland fields as close to the house as possible or turning upland rice fields to fallow after several years of cultivation, to become a rule, it had to be either repeated by many players independently or agreed upon by all the participants as the usual way to do things in the context of their village. The same was true for the parameters of the model they were constructing jointly, e.g., yield of main crops, labor requirements for each of their actions; these resulted from a consensus among all the participants and were often the occasion for lively discussions. At the end of each round of the game, the income generated from the different activities was computed, and the players received virtual money computed as rice equivalent. This reward for their decisions and actions was first reinvested in basic food consumption. When the financial balance of a household agent was positive, he or she was able to buy pigs or buffaloes or nonagricultural products. Conversely, when the balance was negative, the household agents had to borrow money from others or from the bank or engage in off-farm activities. About $6 \mathrm{yr}$ could be simulated in the successive rounds of the game, and the one-day session ended with a collective debriefing. All the actions of the individual players were recorded along with all the interactions and discussions. The role-playing game proved to be a very powerful tool that enabled us to observe the actions of the player-farmers, elicit their decisions in context, and discuss with them the land use that would result from the actions they had undertaken in the gaming simulation (Greenblat 1981, Castella et al. 2003, Boissau et al. 2004). The rules of the RPG were intentionally kept very open to allow the players to explore solutions that the researchers might not have included in the model or that the players themselves might not dare to risk in real life. This brought to light valuable information about how farmers deal with risk and uncertainty and how they adapt to changing circumstances or to an unexpected outcome of a decision they made. 
Contrasting strategies of the players were identified, including repetition, imitation, innovation, and cooperation. The behaviors that had been used during the game were then discussed collectively and linked with stories or events that had really happened.

During the following three days, two processes were undertaken in parallel:

- Individual interviews were carried out with the players to understand the rationale behind the actions they had undertaken during the game. They were asked to justify their actions round after round, for example, with regard to their economic situation, their past actions, the actions of the other players, their real-life situations, etc. These questions were intended to help us understand what had happened during the game. The interviews also tackled the question of the difference between the game and reality from both a general and a more individual point of view. Finally, the interview ended with an assessment of the game by the interviewee.

- A computerized multiagent simulation of the game was implemented. The model, and especially the behavior of the agents, was based both on our observation of the game and on the information obtained during the individual interviews. This first model was intended to replicate as faithfully as possible the sequence of the game, by specifying only general rules for individual behaviors and land-cover dynamics, as identified during the two previous steps. These rules were then used to simulate potential scenarios identified by the participants, for example, scenarios with population growth or with additional rules governing land and/or livestock management.

On the fifth day, a collective meeting was organized with the game participants to present the computer simulation. The session typically started with the presentation of the simulation that replicated the game session they had played a few days before. Through this presentation, the players became familiar with the computer model and learned to follow a simulation on the screen. For example, they were able to describe the changes in the landscape and to infer the behaviors of the agents. Other scenarios were then presented to the participants and discussed. Computer-simulated scenarios allowed us to simulate, in a shorter time, longer periods than those used in the game and therefore to show farmers the long-term implications of their choices. The discussion focused in particular on the similarity between the simulated scenario and past, present, or future reality; the likelihood of the scenario actually happening; the problems that would result; and possible ways of solving them (Boissau and Castella 2003).

\section{Building trust through a gaming-simulation approach}

The role-playing approach can overcome the main obstacle to data collection encountered in traditional inquiries using questionnaires, open discussion, or rapid participatory appraisal, which is the lack of trust between the interviewer and the interviewee that may result in imprecise or inaccurate information. Interviewers and interviewees usually come from different social environments and have different cultural backgrounds. These differences become especially acute when local people from ethnic minorities of the mountains are confronted with researchers from the Kinh group, who dominate Vietnam's national research system, or with foreigners from international organizations. In addition, interviewers and subjects have little or no contact with each other before or between interview sessions, which does not facilitate easy communication. Traditional ethnographic studies built trust between the investigator and local people through long-term direct observations that are only possible if the researcher can share the life of the local community for long enough periods. As mentioned above, the approach described here builds upon very valuable monographs that have contributed considerably to our understanding of local circumstances, but are nevertheless not sufficient to achieve the objective of a scale transfer in such a diverse environment.

Another obstacle to communication when working in Vietnam, especially in northern mountainous regions, is the fact that interview subjects are often pressured into spouting the official line rather than expressing their own points of view. Farmers, especially those from ethnic minorities, generally have a low level of education and are not considered by local authorities to be knowledgeable people. 
Fig. 2. The game board used for the SAMBA role-play. (Photograph by J. C. Castella)

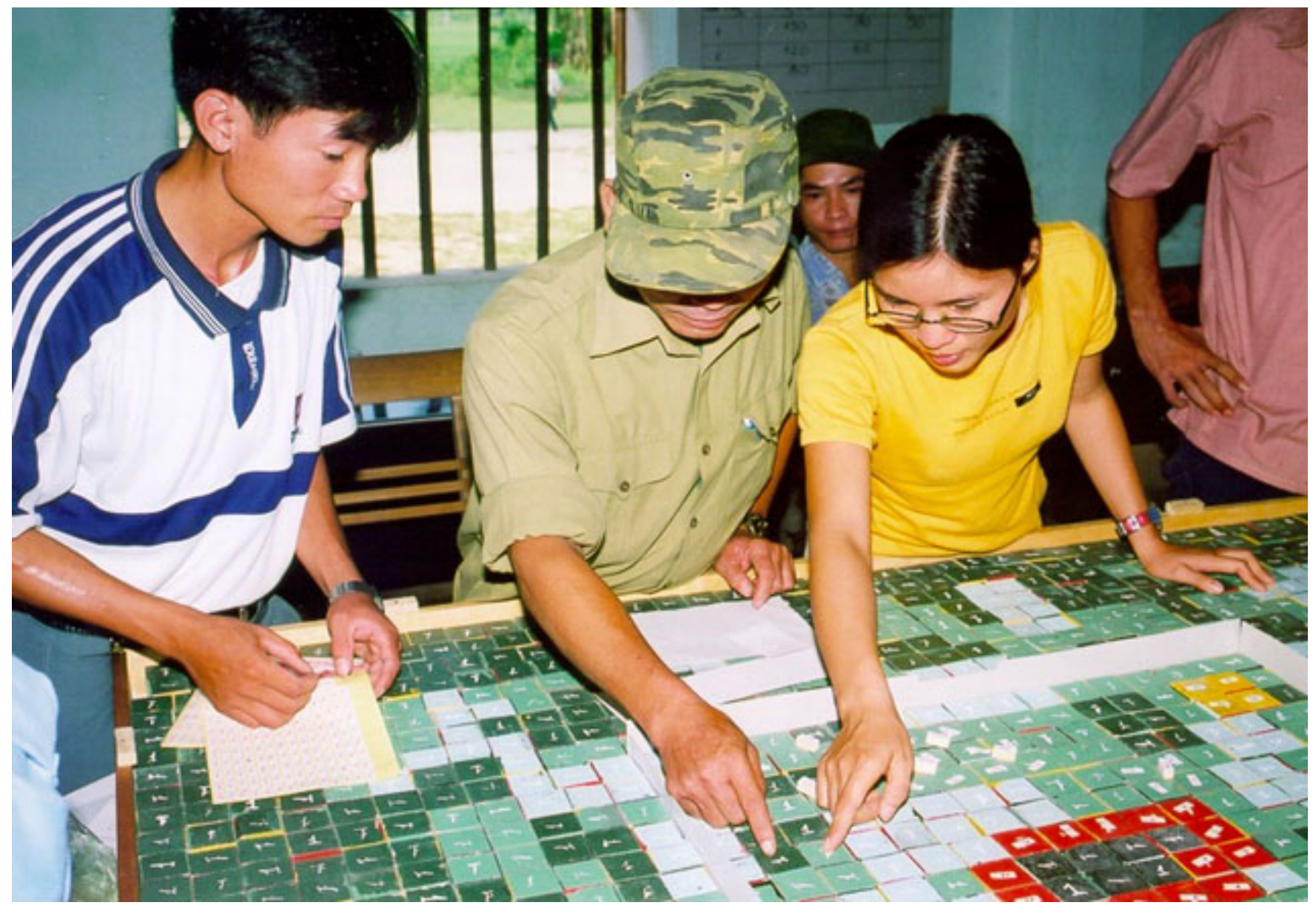

Authorities often see them as backward peasants who make irrational use of resources. Consequently, these farmers are given little opportunity to express their views in public, or they may only be allowed to speak under the control of the authorities, who make sure they repeat official views on the subject, thus eliminating personal opinions and passing over conflicts in silence. To understand a specific situation or why farmers adopt certain practices, one has to go beyond this official discourse, although this can only be achieved by using an unconventional means of communication such as role-playing. Participants were very enthusiastic about the game because they felt it gave a voice to people who are not often heard. One participant told us, "... if you really want to understand me, it's better to watch what I do than listen to what I say about it." Using gaming simulation, we were able to both observe the actions of the players directly and see how they changed over time, especially in periods of crisis. The game also served as an ice-breaker. During the role-playing sessions, players, observers, and researchers shared a common experience that helped create links between them. This considerably facilitated subsequent interactions, starting with individual interviews during which a real enhancement of communication was observed.

\section{Relationships between the gaming simulation and reality}

During the sessions of the role-playing game (RPG), the farmers played the role of farmers. Our 
observations during the game showed that they all played seriously and did their best to manage their resources as they do in real life (Boissau and Castella 2003). During the first rounds of the RPG, they systematically used their own experience as a reference for making decisions. However, they were not playing exactly the roles they fulfilled in real life because they had drawn cards that defined the composition of their virtual families and their resource endowments. The aim here was to avoid reproducing in the game existing relationships or potential tensions between participants. In this way they were able to react to unknown situations and even to make fun of themselves and of the consequences of their decisions in a relaxed atmosphere. Rather than investigating the real lives of the participants, the purpose of the game was to create a shared representation of their livelihood system based on their knowledge of the local context, and more generally to capture the system of representation shared by all members in their community. Because it was not possible to get the whole village (50-100 households) around the game board to play the game, we made the assumption that players from 10 carefully selected households could reconstruct the history and institutions of their village through their interactions in the game (Bousquet et al. 2002, Etienne et al. 2003). The debriefing at the end of each session in the presence of the village committee helped eliminate possible bias in the selection of participants or in the participatory processes. The discrepancies between the outcome of the role-playing and the villagers' own representations of their situation were discussed collectively during the debriefing and then individually during the interviews that followed the role-playing. These successive interactions and repeated adjustments of the local agent-based model resulted in a common agreement on the way the game represented their reality (Castella et al. 2003).

At each site in which SAMBA-Week was implemented, the results obtained were consistent with information acquired from other sources such as secondary data and monograph studies, which provided a second level of validation of the model. The bidirectional communication favored by the combination of role-playing and the computer model resulted in an original perspective that it would be impossible to achieve using traditional survey methods. Based on the common experience of the game, subsequent discussions and simulations helped elicit local rules, both official and informal, for resource management. Farmers were not talking about what they usually did in a normal year; they were giving the reasons for their actions at the same time as they made their decisions.

\section{SCALE TRANSFER OF LOCAL MANAGEMENT RULES TO A REGIONAL LANDSCAPE}

\section{Structure of the agent-based model and participatory generation of the rules}

The whole SAMBA-Week process was applied in five of the six communes of Bac Kan Province in which monograph studies had previously been implemented. By repeating SAMBA-Week in different environments, it was possible to capture the diversity of local situations and study local trajectories of changes in land use. This resulted in a very rich interdisciplinary database comprising five location-specific SAMBA models of resource management in the form of (1) records of the roleplaying games, (2) computer models containing multiple scenarios explored with local farmers, (3) individual interviews that helped elucidate the decision-making processes of the farmers, and (4) the results of the monograph studies, i.e. a comprehensive study of land-use change based on farming-system typologies, land-use maps, the identification of stakeholders, the analysis of their strategies, etc.

\section{A generic decision-making model with local adaptations}

All model artifacts, i.e., the agent-based model (ABM) designed by scientists, the role-playing game (RPG), as well as a location-specific ABM resulting from the participatory process, were organized around the same basic rules/algorithm that structured the conceptual model derived from the monograph studies (Castella et al. 2005). In the SAMBA model, farm households make decisions about their production activities based on their capacity to supply the rice needs of their families from their own paddies. Thus, they might decide to intensify rice cultivation in the lowlands, e.g., by introducing a second rice cycle in the spring, or to grow upland rice on the hillsides. Only after rice self-sufficiency had been achieved would farmers diversify their production or produce cash crops for 
the market. All the results we obtained from different sources confirmed this behavior, even in areas with good access to market that would make it possible for farmers to sell agricultural products and buy rice for home consumption. This is certainly one consequence of the long period of food shortage in the early 1980s and also underlines the cultural value of rice cultivation in Vietnam. A second hypothesis underlying the model is that farmers make their decisions regarding land use based primarily on their access to paddyland and not because of cultural values specific to their ethnic group (Castella and Dang 2002). Consequently, the decision-making rules would be the same for all ethnic groups in the computational model, and their different behaviors would emerge from differences in their access to land resources.

Around these fundamental rules that are central to the decision-making model, the successive SAMBA-Weeks incorporated specific local characteristics. The type of agricultural production and its productivity would vary with biophysical conditions such as soil and topography and with socioeconomic context, e.g., accessibility, presence of government projects, etc. Thanks to a parameter interface (Fig. 3), the computational model can be parameterized as a function of specific local characteristics as expressed during the participatory simulations, e.g. average crop yields as a function of soil quality and climate, the speed of forest regeneration, or livestock reproduction patterns. This interface was used to rapidly adapt the model to local circumstances or to simulate with local stakeholders the effect of changing parameters on the behavior of the model.

\section{Spatial and temporal scales}

Because the time and spatial scales are related, tactical decisions made during a cropping season do not have the same impact on land cover as do strategic decisions involving changes in land use. The SAMBA model focuses on the second type of decision, which determines both the time step (1 yr) and the spatial resolution of all the grids used in the RPG, ABM, and GIS (1000 $\mathrm{m}^{2}$, equal to 1 bung: the unit used to measure area in mountainous areas of northern Vietnam). The choice of these complementary scales and spatial resolution had serious implications for the diagnostic study of past changes in land use and for the scenarios of future changes. Although the extent (village), the grain resolution (1000 $\mathrm{m}^{2}$ cells), and the frequency (annual time step) of the observations were the same in the monographic case studies (MCS), RPG, or ABM tools, the methods differed in terms of the time span of the observation: $2-3 \mathrm{yr}$ in the MCS, 6$7 \mathrm{yr}$ in the RPG, and up to 20-30 yr in the ABM. In addition, the $A B M$ made it possible to incorporate all the village households into the simulation, although only 10 of them were actually represented during each RPG session. The fact that these three tools were complementary greatly facilitated the interactive process of analyzing short-, medium-, and long-term scenarios with stakeholders. Although the agent classes (Fig. 4 and Appendix 1) and core architecture of the computational model remained the same all through the participatory simulation process, i.e., the fifth day of the SAMBA-Week, the environment and initialization procedures were changed only gradually to enable the participants to follow. Once they were acquainted with the SAMBA model through the game-based discovery process, we simulated landuse changes on the computer screen using ABM running on the $25 \times 25$ cell grid similar to the game board (Fig. 5A), then on a $50 \times 50$ cell grid that featured a more realistic landscape (Fig. 5B). In the first case, the model was initialized with the simplified environment of the village and the characteristics of the 10 players of the RPG, whereas in the second case it was initialized with a more complex environment, i.e., with the same proportions of land-use classes as in the real village, and with 50 household agents parameterized according to the birth registry database of the village. Under this configuration, the model supported long-term simulations involving 20-50 time steps and therefore incorporated a population increase that was not necessary when representing the six time steps played during the game.

\section{Coupling agent-based models and GIS to extrapolate land use/cover change analysis across the landscape}

After a few applications of SAMBA-Week, the model started to stabilize, and new applications brought decreasing levels of relevant information to improve the model. Throughout our five sessions of participatory simulations, the ABM was calibrated by introducing new methods in the form of elementary algorithms describing how the farmers managed natural resources through farming, forestry, or animal husbandry activities that were specific to certain environments, village 
Fig. 3. Parameter interface of the SAMBA-GIS model. Units: labor capacity of worker (x $1000 \mathrm{~m}^{2} /$ worker), yield of crop $\left(\mathrm{kg} / 1000 \mathrm{~m}^{2}\right)$, prices in Vietnamese dong or VND (U.S. $\$ 1.00=19,000$ VND in 2004), consumption (kg of equivalent rice/person).

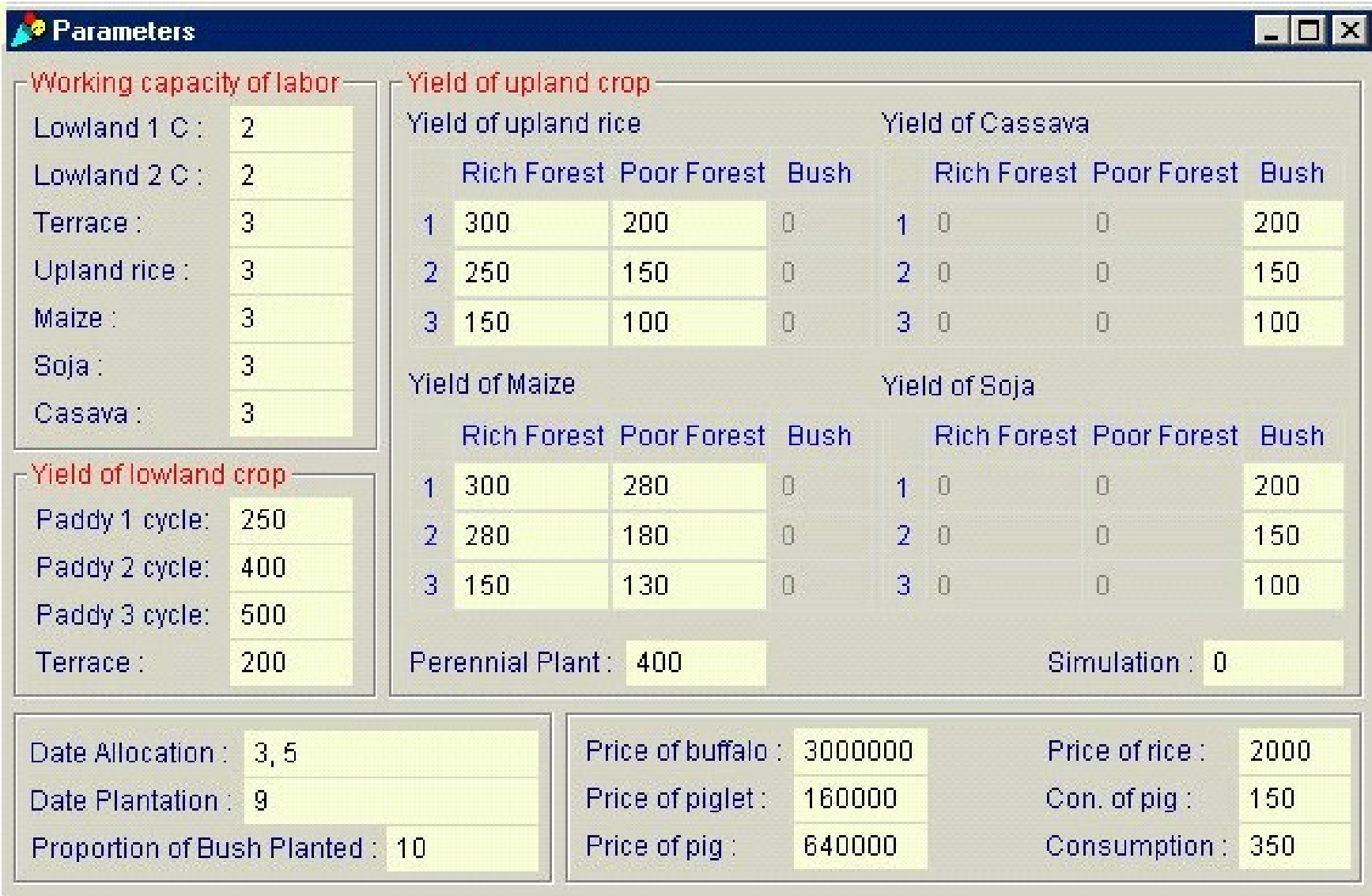

communities, or development projects. These methods, e.g., createFieldHut, intensifyLowland, were incorporated into the programming sequence together with the conditions, e.g., threshold on cell qualities, labor force available, density of agents, etc., that triggered their implementation during the simulation (Fig. 6). The model evolved to incorporate new layers of information that agents take into account when making decisions, e.g., soil types, accessibility, reforestation plans, and also to incorporate new rules observed at different sites. The new model was more realistic than its previous versions and, at the same time, it resulted from an effort of decontextualization. When the same algorithm was applied to the whole province, the results of the simulations varied considerably between villages depending on the geographic distribution of the natural resources in the different layers of the GIS and on the local conditions extracted from the parameter interface. When the model was used for a batch simulation of all villages, parameters specific to each village were loaded from a database under MSAccess ${ }^{\circledR}$. The initial conditions of the agents, e.g., number of households, household composition, livestock, etc., were extracted from the same database. The environment is represented as a grid that can be either a simplified representation of a landscape generated directly under Cormas platform (Fig. 5B) or a real land-use map of the village extracted from a GIS under ArcView ${ }^{\circledR}$, with each layer saved as an ASCII file (Figs. 5C and 7). As shown in Fig. 4, the main layers used to initialize the environment are land use, soil type, remoteness computed as the distance to the 
Fig. 4. The agent classes of the SAMBA model. The top box shows the attributes and the bottom box the methods associated with each entity (see Appendix 1).

\begin{tabular}{|l|}
\hline \multicolumn{1}{|c|}{ Household } \\
\hline IDHousehold \\
mouthsToFeed \\
laborForce \\
surplusLabor \\
members \\
landUse \\
buffaloes \\
pigs \\
wallet \\
\hline initialization \\
computeSurplusLabor \\
growUR \\
growFT \\
growOnSM \\
growOnMosaic \\
growOnSlope \\
constructTerrace \\
intensifyLowlandTo2C \\
intensifyLowlandTo3C \\
plantation \\
OffFarmActivity \\
createFieldHut \\
growAroundHut \\
computeIncome \\
sellPig \\
buyPig \\
buyBuffalo \\
reproductionBuffalo \\
managementBuffalo \\
\hline
\end{tabular}

\begin{tabular}{|l|}
\hline \multicolumn{1}{|c|}{ Farmer } \\
\hline $\begin{array}{l}\text { IDHouseHold } \\
\text { age } \\
\text { sex }\end{array}$ \\
\hline init \\
increaseAge \\
\hline
\end{tabular}

\begin{tabular}{|l|}
\hline \multicolumn{1}{|c|}{ Cell } \\
\hline state \\
IDHouseHold \\
age \\
oldState \\
yield \\
remoteness \\
suitablePaddy \\
suitableMaize \\
suitableUplandCrop \\
soilType \\
\hline init \\
increaseAge \\
regeneration \\
\hline
\end{tabular}

\begin{tabular}{|l|}
\hline \multicolumn{1}{|c|}{ Buffalo } \\
\hline IDHouseHold \\
age \\
sex \\
interval \\
\hline init \\
increaseAge \\
movement \\
mortality \\
damageCrop \\
\hline
\end{tabular}

\begin{tabular}{|l|}
\hline \multicolumn{1}{|c|}{ Pig } \\
\hline IDHouseHold \\
\hline init \\
\hline
\end{tabular}

residential areas, and land suitability for the main crop computed from topography, soil characteristics, and crop requirements. At each time step, the environment is transformed by the actions of household agents following the sequence shown in
Figs. 6 and 8 . The cells can be appropriated by a household, and the land can be converted to different uses such as paddy rice, upland rice, cash crops, and fallow according to the household's strategies. The land cover also changes according to specific rules 
Fig. 5. The different environment grids used in the participatory simulation: (A) abstract landscape of the game board, (B) abstract landscape of the agent-based model (ABM) corresponding to the composition of the village landscape, $(\mathrm{C})$ realistic landscape uploaded in the ABM from the village GIS. The colors show the different land uses of each $1000 \mathrm{~m}^{2}$ cell: dark green $=$ dense forest, green $=$ open forest, light green $=$ shrub/fallows, dark blue $=$ tree plantation, yellow $=$ upland crops, red = paddy field, black = residential area.

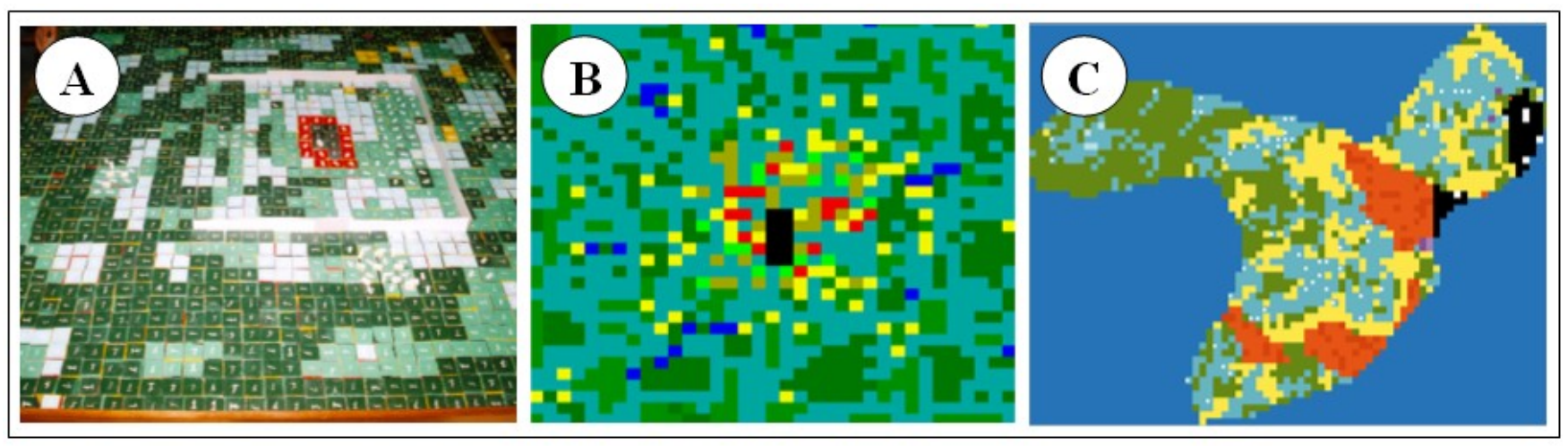

of vegetation dynamics. The land-cover "state" of a cell changes with its age, which is incremented at each time step. In addition, grazing livestock has a negative impact on forest regeneration. Under the Cormas platform, the simulation can be monitored using different views, i.e., layers of information about the environment and the agents as shown in Appendix 2.

To check the model parameters, we verified that, once initialized with the biophysical data for land cover in 1990 and soil types and socioeconomic data on the population, livestock, and accessibility of the 50 villages in the case study sites, our model would be able to retrieve the same scenarios as the one elaborated during SAMBA-Week with the localityspecific ABM. In addition, a sensitivity analysis was performed on a number of parameters such as individual food consumption, crop productivity in the paddies and on the hillsides, and the working capacity of labor units that were assumed to vary between locations. The model was run 20 times over 20 time steps for increasing levels of the parameter values. For example, we checked that increasing food demand induced intensification of agriculture in the lowland when feasible, then expansion of upland cultivation, and, last of all, income generation from nonagricultural activities, as observed in reality. By comparing the outcomes of different agent initialization procedures, we also checked a key assumption of the model, i.e., that access to lowland fields, rather than ethnicity and related cultural factors, was the major determinant of the farmers' decisions. Based on the results of these tests, more layers of information were incorporated to account for (1) the influence of village accessibility on the range of livelihood options available to farm households and (2) the existence of local opportunities for income generation, e.g., mining, small agro-industry, or specific development projects, e.g., reforestation, poverty alleviation programs. Maps representing the areas of influence of these off-farm activities or projects were added together with the corresponding rules. The village trajectories of land-use change for the 221 villages of Cho Don District were then compared with the results of the MCS and SAMBAWeek at the reference sites. This led to a typology of villages based on key indicators identified through the MCS, including access to paddyland and endowment in natural resources with respect to the active population, and land-change trajectories simulated with SAMBA-GIS. This made it possible to deduce the driving forces of land change at work in any village in the district from its resource endowment and recent patterns of change in land use (Castella and Dang 2002). Specific actions could consequently be targeted to the different types of villages according to the driving forces currently at work, e.g., lack of irrigated land, poor access to 
Fig. 6. Diagram representing the farmers' process of decision making when allocating their production means to different land-use systems. WFP stands for the World Food Program, a reforestation program that supplied $500 \mathrm{~kg}$ of rice for three consecutive years to farm households for each hectare of timber trees planted and protected. $\mathrm{LF}=$ labor force available.

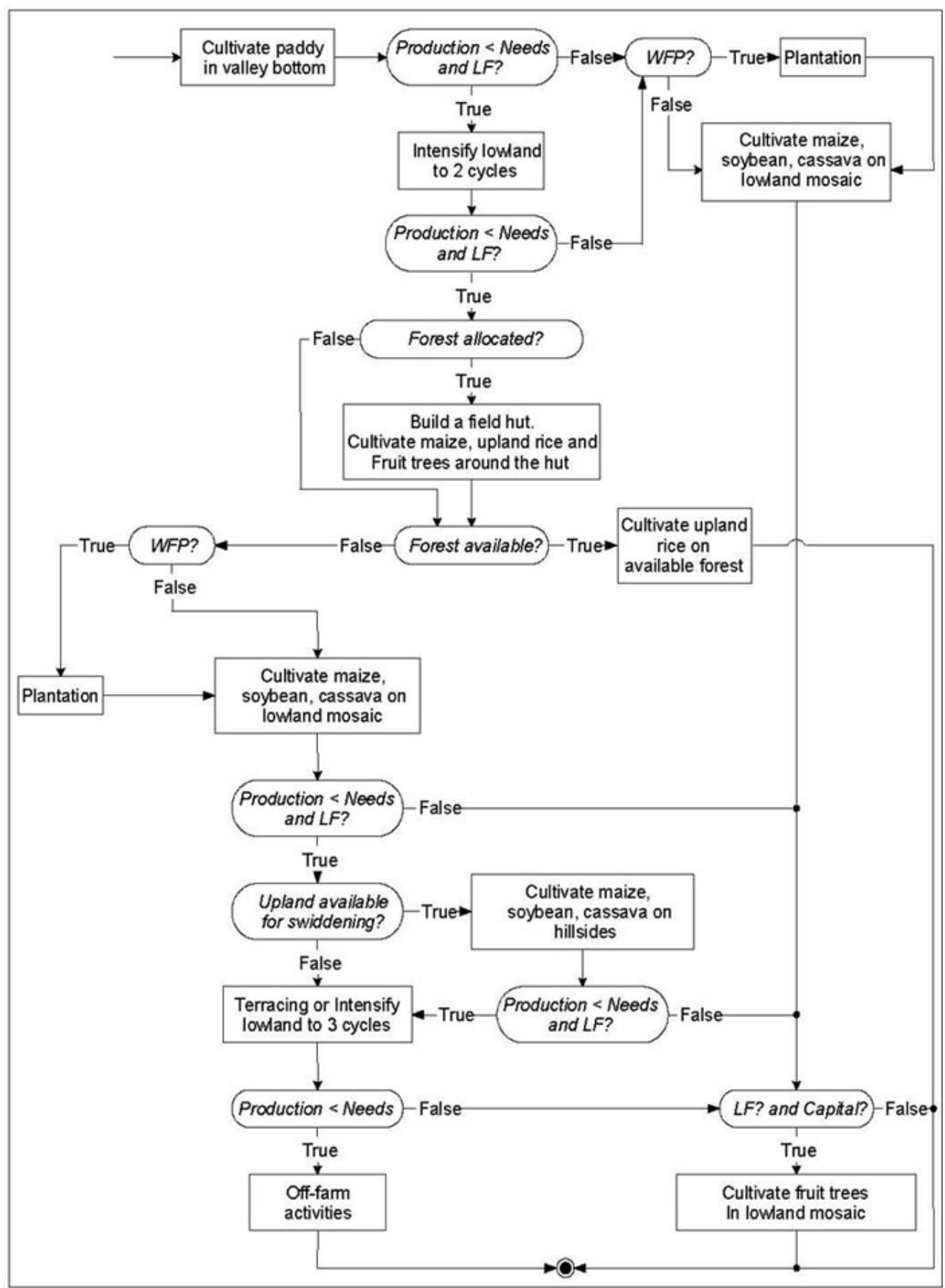


Fig. 7. Initialization of the model environment under Cormas from the raster GIS under ArcView®.

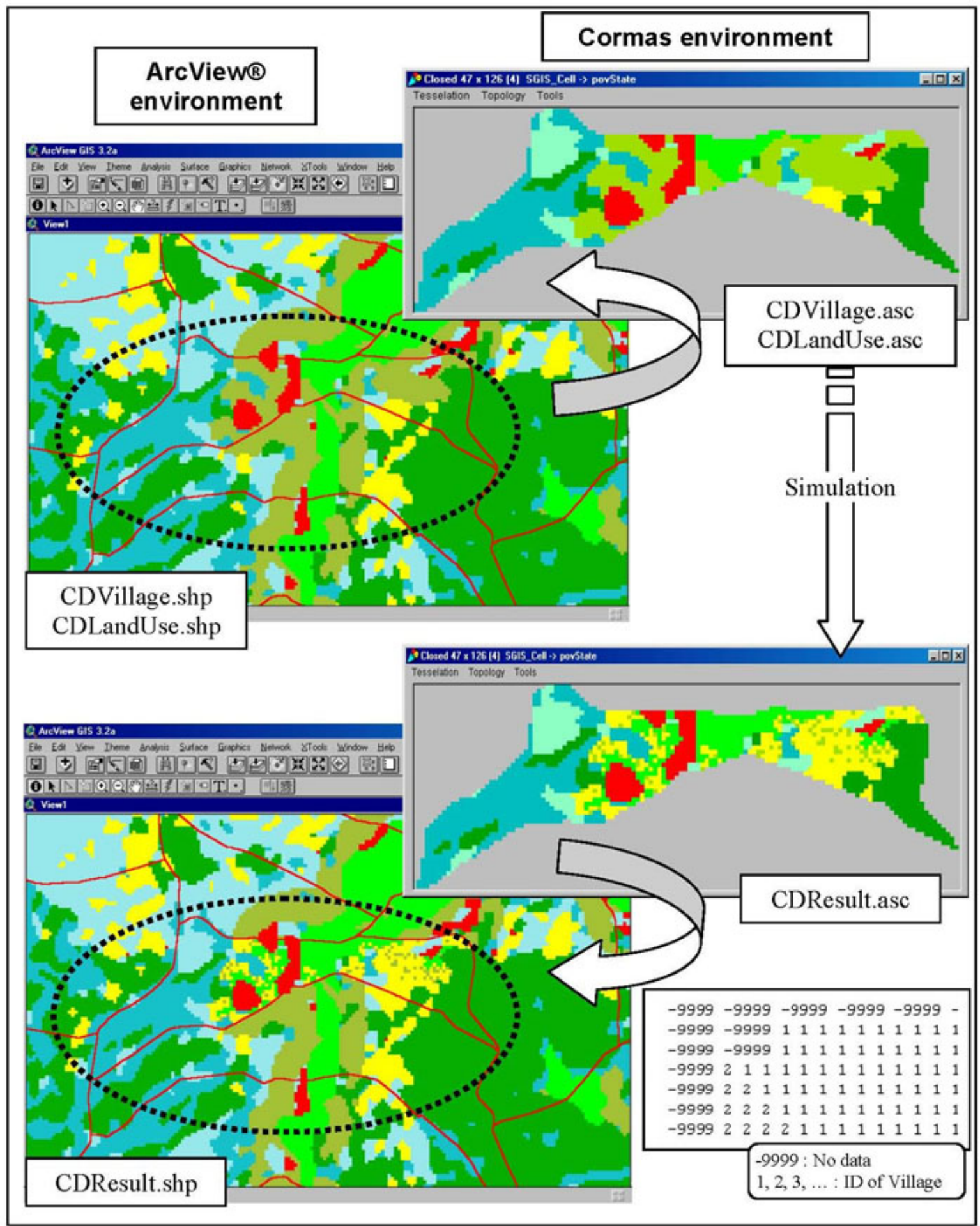


Fig. 8. The sequence of action at each annual time step of the SAMBA model.

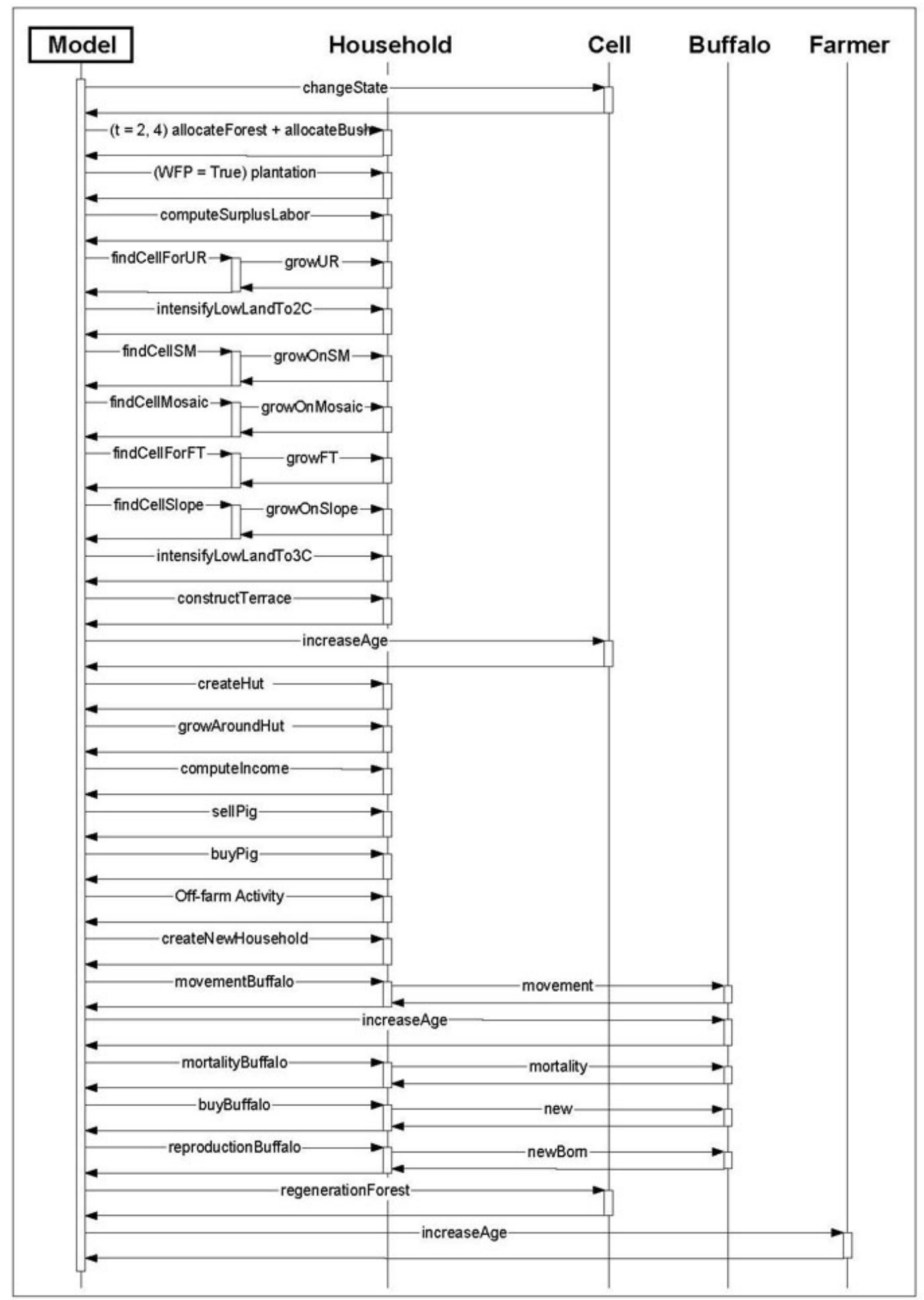


market, etc. The results of the communication platforms conducted at the reference sites were able to inform policy makers about the development issues at stake in each type of village (Castella et al. 2004).

\section{Validation of the regional agent-based model for land use/cover change}

The SAMBA-GIS model was validated in one district of the province, Cho Don District, in two successive stages.

First, land use/cover change (LUCC) over the period 1990-2001 was simulated for each village in the district. The model was initialized with secondary data complemented when necessary with data from rapid village surveys on population, ethnicity, number of buffaloes, presence of reforestation or development projects, etc., and GIS layers related to land use, soils, accessibility, etc. The resulting maps were aggregated after each time step to recreate the district map from the simulated village maps. Next, the simulated land-use maps were compared to the actual land-use maps available for 1995, 1998, and 2001 from satellite images and to statistical data on agricultural production in the district (Fig. 9). The coherence of the trends representing changes in land use among the three sources of data provided the first level of validation. Because of the stochastic elements of the model, e. g., location of the households on the map and a randomized search procedure for cells suitable for different activities, the map outputs of several runs of simulation were compared to the map that was the result of remote-sensing observations. The differences between the observed and simulated maps were assessed in terms of the quantity of cells rather than the exact location of the changes in land use. A more refined comparison of the simulated and observed maps has since been undertaken based on the comparison of landscape metrics at the village and district levels. The method used is reported in Pontius et al. (2004). In our context of action-research, this kind of validation was sufficient to classify villages according to their main land-use system, given the contrasted land-change trajectories at the study sites, e.g., rapid deforestation linked to swidden cultivation in villages in which access to paddyland is limited, forest regeneration after forestland allocation where paddy cultivation could be intensified, etc. The model was able to satisfactorily represent land changes observed by remote sensing data throughout the 1990s (Fig. 9). However, the decision-making rules in the model may not correspond to the actual decision-making process of the farmers because several different algorithms may lead to the same landscape output.

Consequently, an actor-based validation procedure was tested in two communes of the district in which the projects had not previously been carried out (Fig. 1). At each site, SAMBA role-playing by 10 village headmen from the commune was the first activity in a day-long validation session. The participants then learned the decision-making rules of SAMBAGIS during a step-by-step simulation with the ABM. When they felt comfortable with the computer environment, we replaced the basic grid with the raster GIS of the villages. Village headmen were placed in decision-making situations that were designed to explore different types of decisions depending on the availability of resources, local institutions, environmental factors, and the behavior of other players. Based on this simulation, we were then able to discuss with the village headmen the changes that had occurred in their villages, and together we tried to explain any discrepancies between the history of the village land use simulated on the computer screen and the history known by the local stakeholders. The consistency between these scenarios repeated for 20 villages provided the second level of validation, which can be referred to as "social validation." What was measured was the level of satisfaction of the local stakeholders involved in the participatory simulation with the way the recent transformations of their village were represented in the model.

\section{LIMITS OF THE PARTICIPATORY SIMULATIONS OF LAND USE/COVER CHANGE AND FUTURE OUTLOOK}

\section{From validating to legitimizing the decision- making model}

Land use/cover change (LUCC) models have to be carefully validated if they are to be used to support collective decision-making or action (Lambin et al. 2003, Parker et al. 2003, Pontius et al. 2004). What needs to be validated, and for which purpose, should guide the validation procedure (Manson 2002). The successive stages in the implementation of the multiscale participatory diagnosis of land-use 
Fig. 9. Comparison of simulated maps and actual land use maps used to check the SAMBA-GIS model.

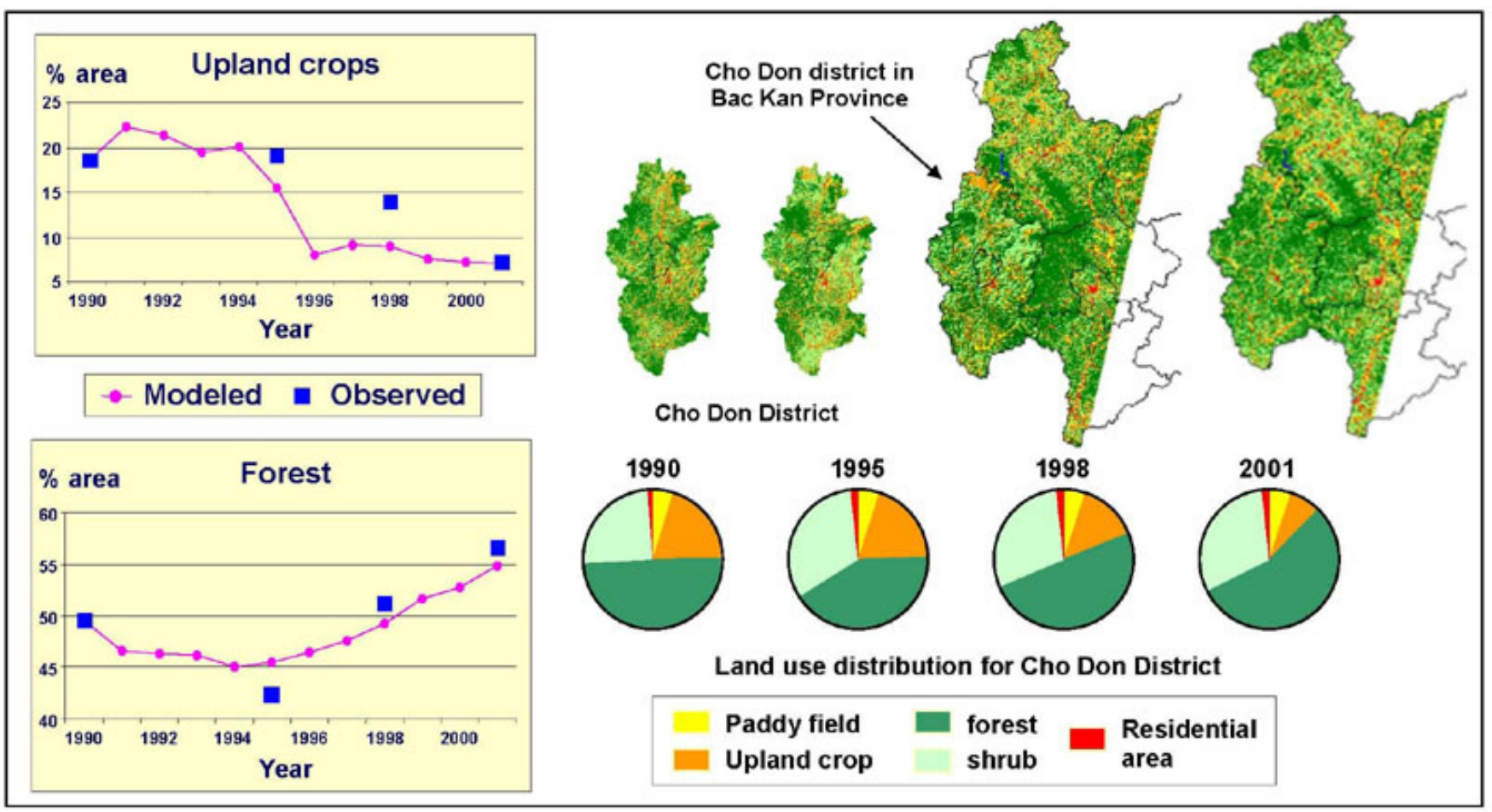

changes, which are summarized in Fig. 10, provided the occasion to cross-check the information obtained from different sources. At the local level, i.e., the village or commune, monographic case studies (MCS), the classic method of data collection and analysis, were combined with the participatory simulation based on agent-based models (ABM) and role-playing games (RPG) through an iterative process of formulation and testing of hypotheses, e. $\mathrm{g}$., the farmers' level of self-sufficiency in rice from the paddies determines the activities they carry out on the hillsides and their access to land resources determines their strategies much more than ethnicity or cultural values. In addition, the aim of the RPG was to elicit and validate the decision-making process of local farmers. Information gathered through role-playing and individual interviews was incorporated into a multiagent model. When simulating the consequences of decisions made by individual farmers on changes in landscapes, the ABM-LUCC model deals with the question of scale transfer (Bousquet and Le Page 2004). In our case, we also dealt with a second level of transfer: from the local to the regional scale (Fig. 10). Although a model resulting from a participatory simulation session can be considered valid or legitimate for the study site under investigation, it is locality-specific and may not apply to other sites. Extrapolation of locality-specific data to regional landscapes may thus require complementary validation procedures (Manson 2002).

During the process of modeling, the consistency of information can be checked by the scientists: the outcomes of agents' behavior must lead to a global environment that closely resembles the one observed in the participatory simulation session. If this is not the case, individual behaviors must be investigated further. However, resemblance is a subjective notion even for scientifically grounded methods of map-to-map comparison (Pontius et al. 2004). Much effort can be invested in assessing the resemblance between simulated outputs and empirical data with little operational usefulness in the participatory process (Manson 2002). We thus relied on the expertise of the scientists involved in 
Fig. 10. Successive stages in the multiscale participatory simulation of land-use changes. ABM stands for agent-based model.

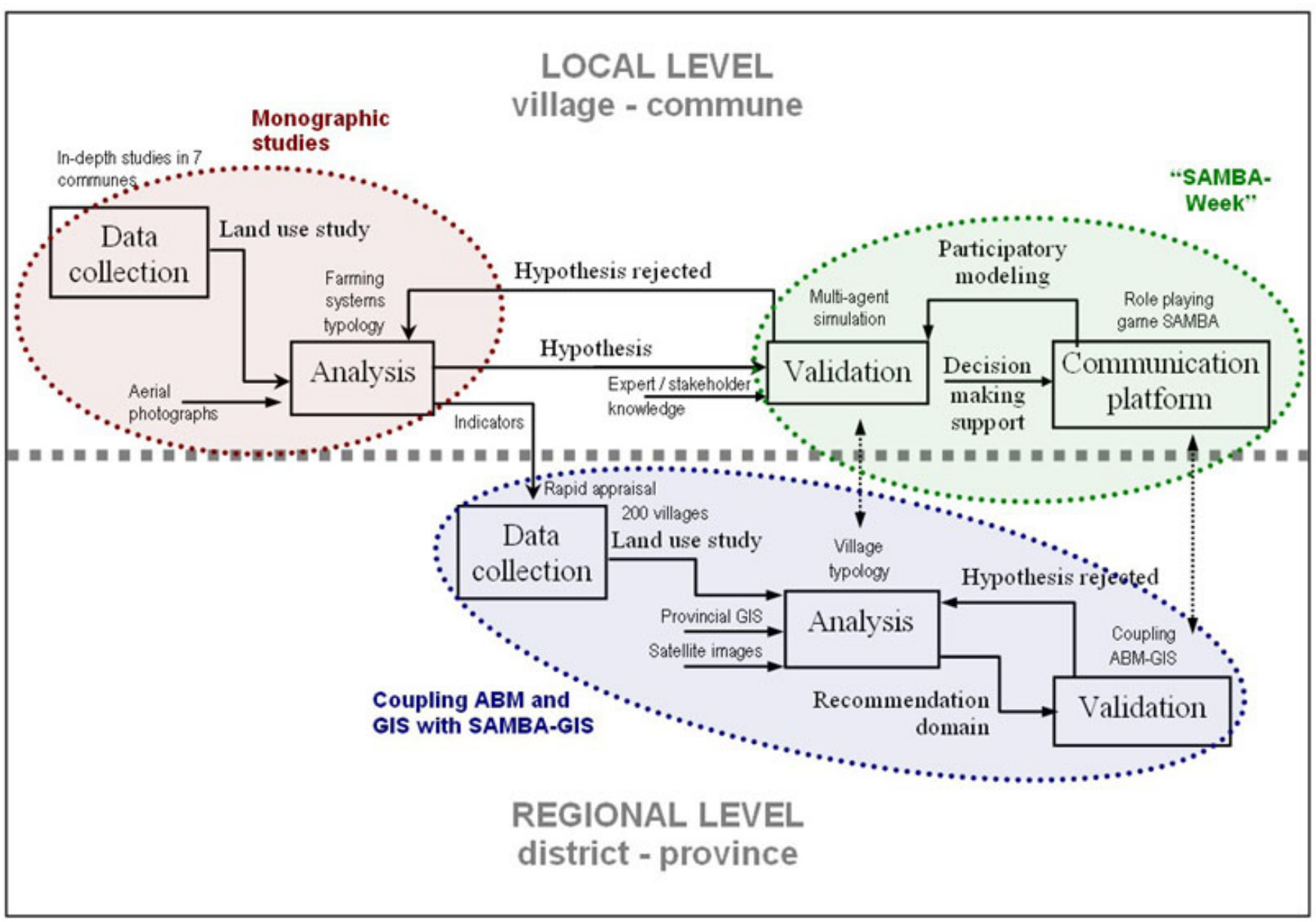

the field work over the 4 yr of the research program and, more importantly, on the local knowledge of people who have lived their whole lives in the study area. When the model was presented to the participants, they were asked to validate the model, i.e., accept the computer simulation as a "good" representation of their reality, and to suggest changes to aspects that they considered did not match reality. Once a consensus had been reached on the model, it was considered a common representation of reality shared by both the stakeholders/participants and the researchers. What we call "social validation" should not be interpreted with reference to model validation procedures in natural sciences. In our case, it was more important to legitimize the model with its end-users through a collective learning process than to provide evidence for the scientific community. Indeed, a model can only be used as a mediating tool for concerted action once it has been perfectly understood and is considered by decision makers to be legitimate (Barreteau et al. 2001).

\section{Supporting collective decision-making and negotiation}

Once the black box of the model has been opened thanks to the role-playing sessions, i.e., the rules have been made explicit to all participants, it can be used to support collective action (Barreteau et al. 2001). Through the participatory simulation, 
individual farmers who usually have only a partial view of their village agro-ecosystem contribute to building up a complex picture of the system, which broadens their perception of the problems and, as a consequence, also extends their range of action. They become more fully aware of the differences between the local stakeholders and of their interdependency in managing village resources (Ravnborg and Westermann 2002). They feel empowered by the recognition afforded by the group of their contribution to the common representation of the system. Through the participatory simulation, people who are not familiar with computers and even illiterate people are able to grasp the model structure and rules. As soon as they feel comfortable with the model, they start suggesting changes to the rules or parameters of the agent-based model to test different hypotheses or elaborate new scenarios. They get involved in a communication platform that promotes a shared representation of the issues at stake (Röling 1994, Röling and Jiggins 1998, Steins and Edwards 1999).

To give an example, the participants at one session were concerned about the problems associated with a government reforestation program that had reduced the amount of grazing land available to their commune. The forest plantations were still young, and farmers wanted to evaluate the time remaining before these problems would become serious, and who would be affected. They also wanted to assess the extent of the problems and their possible consequences for the whole community. Together we built several scenarios and assessed the risk associated with each, e.g., reduction in the size of the village livestock herd, specialization in animal husbandry by some farmers, limitation of the reforestation scheme, introduction of forage as a cover crop associated with upland crops, etc. After the collective experience that all the participants had shared for one week, we were all partners in the solution-finding process. During the last day of that SAMBA-Week, lively discussions and negotiations based on mutual trust tended to minimize tensions between people with different objectives, viewpoints, or strategies. The scenarios were able to introduce technical and/or organizational innovations and, most importantly, discussions of social factors that would facilitate the adoption of these innovations. The project further supported the local people in implementing the local development plans designed collectively through training courses on specific topics of interest and the introduction of technical innovations, e.g., on-farm testing of new forage crops and cover plants for erosion control (Martin et al. 2004).

\section{Institutionalizing the participatory simulation approach}

Although the participatory simulation approach met with very enthusiastic reactions from local people, it was generally perceived by the commune and district authorities as a new extension method and not as a valuable basis for the formulation of policy. However, the authorities did appreciate the opportunity to combine knowledge from different communities, including scientists, experts, and local stakeholders who shared a common interest in sustainable natural resources management. They asked the project team to use the method more widely, to involve more participants from the villages in the communication platforms, and to make more people aware of possibilities for the sustainable management of local resources. They recognized the potential of the approach to favor bottom-up initiatives and to support the local committees of mass organizations such as the Farmers' Association, the Women's Union, and the Fathers' Front and of administrative bodies such as the People's Committee in reviving their activities, especially by favoring the emergence of collective planning and action at the local level. At the same time, they pointed out that not all innovations, be they technical or social, systematically emerge from local negotiations. In some cases, changes that seemed impossible to local people became reality thanks to policies imposed from the top, e.g., financial incentives for agricultural intensification, or to external changes, e.g. improved road networks. The marked disconnection between the method proposed and the way policies are actually planned in Vietnam is one more incentive to reconcile bottom-up with top-down approaches to the management of natural resources (Lovell et al. 2002, Castella et al. 2004). Land-use planners often expect models to predict future changes in land use under different policies or institutional conditions. The policy formulation exercise usually consists in planning a margin of progress based on the current situation, e.g., the percentage of increase in forest cover as compared to the current situation, the percentage of increase in agricultural income. Their search for an optimal solution is conceptually very different from the exercise of the negotiation platform, which consists of collectively reaching a 
solution that is acceptable to all groups of stakeholders who wish to share a common vision of a common problem. In the first case, the solution is imposed from the top, whereas, in the second case, it emerges from the local community. This fundamental difference in the conception of local development is an obstacle to the institutionalization of our proposed action-research framework. Although both villagers and policy makers recognize the legitimacy of the participatory simulation approach and see its potential benefits, it clearly remains a bottom-up approach. Used through a top-down process, there is a risk that it may become a tool to manipulate local populations. Land-use planners arriving with their own, readymade solutions could try to impose it on villagers through an artificial consensus-building process. On the other hand, if policy makers are excluded from the participatory process, as often happened in the past with grassroots development projects, there is a risk that the proposed solutions will not be implemented beyond the geographic area of influence of the project and will end with the end of the project. It is thus essential to go beyond the demonstration of local successes in land-use planning. Training sessions should be organized that involve all groups of stakeholders, i.e., villagers, extension workers, policy makers, and researchers, and stress the potential of the participatory $\mathrm{ABM}$ to reveal the incentives and resource constraints faced by local stakeholders and, subsequently, to help collectively define which of the proposed solutions would be acceptable and feasible.

\section{CONCLUSIONS: A LEARNING PROCESS IN PARTICIPATORY MODELING}

A new methodology generally emerges from specific research questions and from the context in which the research takes place. The complexity inherent in mountain agrarian systems pleaded for (1) gradual outscaling of the geographic domain of investigation from village to district and province, (2) broadening the thematic scope to include interdisciplinary approaches bridging natural and social sciences, and (3) giving more voice in the research process to local stakeholders from farmers to local authorities and policy makers. The innovative action-research approach presented in this paper showed itself to be relevant in tackling these methodological issues in natural resources management (NRM). It proceeded iteratively from simple to more complex representations of system dynamics. This iterative modeling was done in close collaboration with stakeholders who, along with the researchers, developed scenarios using the different artifacts of the SAMBA model. Role-playing games facilitated the collective design of a model of the village agro-ecosystem by all stakeholders, and the agent-based models were a computerized implementation of the model to simulate different scenarios and to visualize the dynamics of changes in land use on the GIS interface. NRM problems identified collectively in specific situations were then extrapolated based on the generic understanding of land-use system dynamics incorporated into SAMBA-GIS. The results were found to be highly integrative, synthetic, and inspiring for local stakeholders as well as for regional policy makers. It provided policy makers with a decision-making support for resource allocation, especially by taking into account the diversity of village trajectories and by eliciting the driving forces of land change associated with each type of village agro-ecosystem. Instead of applying policies uniformly to the whole area under their responsibility, the authorities need to set contextspecific objectives. Once the policy targets are set, the negotiation platforms organized around SAMBA-GIS can help local stakeholders define their own pathway toward the desired goals.

Beyond the results obtained in the specific context of this study in Vietnam, we hope that this experiment will feed a more theoretical debate about producing knowledge that is both scientifically sound and relevant for action at higher, e.g., regional or subnational, hierarchical levels. Understanding agro-ecosystems in their full complexity requires both a high level of disciplinary knowledge and specific mechanisms for the integration of transdisciplinary knowledge. This implies a reconsideration of research processes and mechanisms. From their key role in understanding the dynamics of the system, some scientists are becoming mediators in a negotiation process. Beyond their contribution to unveiling the laws of nature, simulation models are being increasingly used in negotiation platforms to accompany social changes (Röling 1999). Consequently, scientists do not see the model itself as the main outcome of their research, but rather the social change that the model can trigger. Third-party facilitation plays a crucial role in a collective learning process to elicit and contrast the diverging perceptions and interests of stakeholders and to bring these into the open as part 
of facilitating the negotiation of options for improved NRM. As a consequence, strengthening the facilitating skills of the staff of research and development organizations is an important part of efforts to help stakeholders find their own pathway toward sustainability by embedding land-use changes in new social mechanisms.

Responses to this article can be read online at: http://www.ecologyandsociety.org/vollo/iss 1/art27/responses/

\section{Acknowledgments:}

The research presented in this article was developed under the umbrella of the Ecoregional Initiative for the Humid and Subhumid Tropics and Subtropics of Asia, Ecor(I)Asia, convened by the International Rice Research Institute and managed successively by Drs. Paul S. Teng and Suan Pheng Kam. We would also like to thank the three anonymous referees and the seven graduate students who reviewed an earlier version of this article and contributed considerably to its improvement.

\section{LITERATURE CITED}

Barreteau, O. 2003. The joint use of role-playing games and models regarding negotiation processes: characterization of associations. Journal of Artificial Societies and Social Simulation 6(2): 3. [online] URL:

http://jasss.soc.surrey.ac.uk/6/2/3.html.

Barreteau, O., and F. Bousquet. 2001. From a conceptual model to its artifacts: building on experiments using the SHADOC model. Pages 1123-1128 in F. Ghassemi, M. WcAleer, L. Oxley, and M. Scoccimarro, editors. Integrated models for natural resources management across disciplines, issues and scales. MODSIM 2001 (Canberra 2001). Modelling and Simulation Society of Australia and New Zealand, Hamilton, New Zealand.

Barreteau, O., F. Bousquet, and J. M. Attonaty. 2001. Role-playing games for opening the black box of multi-agent systems: method and lessons of its application to Senegal River Valley irrigated systems. Journal of Artificial Societies and Social Simulation 4(2): 5. [online] URL:

http://www.soc.surrey.ac.uk/JASSS/4/2/5.html.

Boissau, S., and J. C. Castella. 2003. Constructing a common representation of local institutions and land use systems through simulation-gaming and multi-agent modeling in rural areas of Northern Vietnam: the SAMBA-Week methodology. Simulations \& Gaming 34(3):342-347.

Boissau, S., Hoang Lan Anh, and J. C. Castella. 2004. The SAMBA role play game in northern Vietnam: an innovative approach to participatory natural resource management. Mountain Research and Development 24(2):101-105.

Bousquet, F., I. Bakam, H. Proton, and C. Le Page. 1998. Cormas: common-pool resources and multi-agent systems. Lecture Notes in Artificial Intelligence (1416):826-838.

Bousquet F., O. Barreteau, P. d'Aquino, M. Etienne, S. Boissau, S. Aubert, C. Le Page, D. Babin, and J. C. Castella. 2002. Multi-agent systems and role games: an approach for ecosystem co-management. Pages 248-285 in M. A. Janssen, editor. Complexity and ecosystem management: the theory and practice of multi-agent systems. Edward Elgar, Cheltenham, UK.

Bousquet, F., and C. Le Page. 2004. Multi-agent simulations and ecosystem management: a review. Ecological Modelling 176(3/4):313-332.

Castella, J. C., S. Boissau, and Hoang Lan Anh. 2003. Enhancing communities' adaptability to a rapidly changing environment in Vietnam uplands: the SAMBA role-play. Pages 203-236 in R. C. Serrano, and R. T. Aggangan, editors. Sustaining upland development in Southeast Asia: issues, tools and institutions for local natural resource management. Philippine Council for Agriculture, Forestry and Natural Resources Research and Development, Los Banos, Philippines.

Castella, J. C., S. Boissau, Tran Ngoc Trung, and Dang Dinh Quang. 2005. Agrarian transition and lowland-upland interactions in mountain areas in northern Vietnam: application of a multi-agent simulation model. Agricultural Systems $\mathbf{8 5}$, in press.

Castella, J. C., and Dang Dinh Quang, editors. 2002. Doi moi in the mountains: land use changes 
and farmers' livelihood strategies in Bac Kan province, Vietnam. Agricultural Publishing House, Hanoi, Vietnam.

Castella, J. C., Dang Dinh Quang, and P. Thévenot. 2004. Toward new modes of governance of the research-development continuum to facilitate the dissemination of agricultural innovations in a mountainous province of northern Vietnam. International Journal of Agricultural Resources, Governance and Ecology 3(1/2):77-94.

Collinson, M. 2000. A history of farming systems research. CABI Publishing, Wallingford, UK.

Conway, G. R. 1985. Agroecosystem analysis. Agricultural Administration 20:31-55.

Dao The Anh and F. Jésus. 1995. Analysisdiagnosis of the agricultural development of a mountain region of North Vietnam. Vietnamese Studies 2:60-99.

Dao The Tuan. 1995. The peasant household economy and social change. Pages 139-163 in B. J. Kerkvliet and D. J. Porter, editors. Vietnam's rural transformation. Westview, Boulder, Colorado, USA.

Etienne, M., C. Le Page, and M. Cohen. 2003. A step-by-step approach to building land management scenarios based on multiple viewpoints on multiagent system simulations. Journal of Artificial Societies and Social Simulation 6(2):2. [online] URL: http://jasss.soc.surrey.ac.uk/6/2/2.html.

Evans, T. P., and H. Kelley. 2004. Multi-scale analysis of a household level agent-based model of landcover change. Journal of Environmental Management 72:57-72.

Greenblat, C. 1981. Principles and practices of gaming-simulation. Sage, London, UK.

Jamieson, N., Le Trong Cuc, and A. T. Rambo. 1998. The development crisis in Vietnam's mountains. East-West Centre, Honolulu, Hawaii, USA.

Johnson, N. L., N. Lilja, and J. A. Ashby. 2003. Measuring the impact of user participation in agricultural and natural resource management research. Agricultural Systems 78:287-306.
Kerkvliet, B. J., and D. J. Porter, editors. 1995. Vietnam rural transformations. Westview, Boulder, Colorado, USA.

Lambin, E. F., H. Geist, and E. Lepers. 2003. Dynamics of land-use and land-cover change in tropical regions. Annual Review of Environmental Resources 28:205-241.

Landais, E. 1998. Modelling farm diversity: new approaches to typology building in France. Agricultural Systems 58(4):505-527.

Leeuwis, C. 2000. Reconceptualizing participation for sustainable rural development: towards a negotiation approach. Development and Change 31 (5):931-959.

Lovell, C., A. Mandondo, and P. Moriarty. 2002. The question of scale in integrated natural resource management. Conservation Ecology 5(2):25. [online] URL:

http://www.ecologyandsociety.org/vol5/iss2/art25/

Manson, S. 2002. Validation and verification of multi-agent systems. Pages 63-74 in M. A. Janssen, editor. Complexity and ecosystem management: the theory and practice of multi-agent systems. Edward Elgar, Cheltenham, UK.

Martin, C., J. C. Castella, Hoang Lan Anh, Y. K. Eguienta, and Tran Trong Hieu. 2005. A participatory simulation to facilitate farmers' adoption of livestock feeding systems based on conservation agriculture in the Vietnam uplands. International Journal of Agricultural Sustainability 2 (2):118-132.

Mazoyer, M., and L. Roudart. 1997. Histoire des agricultures du monde. Editions du Seuil, Paris, France.

Parker, D. C. 2005. Challenges and prospects for integration of geographic information systems and agent-based models of land use. Chapter 18 in D. J. Maguire, M. F. Goodchild, and M. Batty, editors. GIS, spatial analysis and modeling. ESRI Press, Redlands, CA, USA, in press.

Parker, D. C., S. M. Manson, M. A. Janssen, M. Hoffmann, and P. Deadman. 2003. Multi-agent systems for the simulation of land-use and landcover change: a review. Annals of the Association 
of American Geographers 93:314-337.

Pontius, R. G., D. Huffaker, and K. Denman. 2004. Useful techniques of validation for spatially explicit land-change models. Ecological Modelling 179(4):445-461.

Rambo, A. T. 1997. Development trends in Vietnam's northern mountain region. Pages 5-52 in D. Donovan, A. T. Rambo, J. Fox, Le Trong Cuc, and Tran Duc Vien, editors. Development trends in Vietnam's northern mountain region. Volume 1. An overview and analysis. National Political Publishing House, Hanoi, Vietnam.

Ravnborg, H. M., and M. del Pilar Guerrero. 1999. Collective action in watershed management: experiences from Andean hillsides. Agriculture and Human Values 16(3):257-266.

Ravnborg, H. M., and O. Westermann. 2002. Understanding interdependencies: stakeholder identification and negotiation for collective resource management. Agricultural Systems 73:41-56.

Röling, N. 1994. Platforms for decision-making about ecosystems. Pages 385-393 in L. O. Fresco, L. Stroosnijder, J. Bouma, and H. van Keulen, editors. The future of the land: mobilising and integrating knowledge for land use options. John Wiley, Chichester, UK.

Röling, N. 1999. Modelling the soft side of the land: the potential of multi-agent systems. Pages 73-97 in $\mathrm{C}$. Leeuwis, editor. Integral design: Innovation in agriculture and resource management. Mansholt Institute, Wageningen, The Netherlands.

Röling, N. G., and J. Jiggins. 1998. The ecological knowledge system. Pages 281-307 in N. G. Röling and M. A. E. Wagemakers, editors. Facilitating sustainable agriculture: participatory learning and adaptive management in times of environmental uncertainty. Cambridge University Press, Cambridge, UK.

Sayer, J., and B. Campbell. 2004. The science of sustainable development: local livelihoods and the global environment. Cambridge University Press, Cambridge, UK.

Steins, N.A., and V. M. Edwards. 1999. Synthesis: platforms for collective action in multiple-use common-pool resources. Agriculture and Human Values 16:309-315.

Walker, B., S. Carpenter, J. Anderies, N. Abel, G. S. Cumming, M. A. Janssen, L. Lebel, J. Norberg, G.D.Peterson, and R.Pritchard. 2002. Resilience management in social-ecological systems: a working hypothesis for a participatory approach. Conservation Ecology 6(1): 14. [online] URL: http://www.ecologyandsociety.org/vol6/iss1/art14/ 


\section{APPENDIX 1}

Table A1-1. Description of the different entities of the SAMBA-GIS model.

\begin{tabular}{|c|c|c|}
\hline Entity & Attribute & Type \\
\hline \multicolumn{3}{|c|}{ Household } \\
\hline & IDHousehold & Integer \\
\hline & mouthsToFeed & Integer \\
\hline & laborForce & Integer \\
\hline & surplusLabor & Float num \\
\hline & members & Collection \\
\hline & landUse & Collection \\
\hline & buffaloes & Collection \\
\hline & pigs & Collection \\
\hline & wallet & Integer \\
\hline
\end{tabular}

initialization

computeSurplusLabor

growUR

growFT

growOnSM

growOnMosaic
Household code, unique value for each household

Number of household members

Number of persons aged between 16 and 65 in the household

Number of labor force units remaining once workload on paddyland and livestock management is accounted for

An ordered collection of household members

An ordered collection of fields owned by the household

An ordered collection of buffaloes owned by the household

An ordered collection of pigs owned by the household

An integer representing the amount of money, expressed in rice equivalent, owned by the household at the end of each year

Initializes the attributes of the agent

Computes the surplus of workers once workload on paddyland and livestock management is deducted

Selects forest cells to convert to upland rice, first from the land owned by the household, then from the commons

Selects cells cultivated with soybean and located close to the farmer's house to plant perennial trees

Selects cells suitable for maize (flat + soil from limestone) for long-term maize cropping

Selects cells from lowland mosaic (bottom of hillsides close to the valley bottom) to cultivate maize, cassava, or soybean 


\author{
growOnSlope \\ constructTerrace \\ intensifyLowlandTo2C \\ intensifyLowlandTo3C \\ plantation \\ OffFarmActivity \\ createFieldHut \\ growAroundHut \\ computeIncome \\ sellPig \\ buyPig
}

buyBuffalo

reproductionBuffalo
Selects cells from sloping land (hillsides far from residential areas) to cultivate maize, cassava, or soybean

Selects a cell suitable for terracing not currently cropped with paddy

Selects a number of cells for doublecropping (adding a spring rice cycle) from a collection of paddyland cells belonging to the household

Selects a number of cells for triplecropping (adding a winter crop) from a collection of two-cycle paddyland cells belonging to the household

Selects cells for tree plantation in a governmental program from a collection of shrubland and grassland cells owned by the household

Selects a household worker from the collection members to work off-farm when wallet $<0$

Selects a cell in the collection landUse that satisfies the following conditions: close to paddyland or terrace and far from the residential areas

Selects cells close to a field hut and converts land use

Computes the total income of the household at each time step

Selects pigs to be sold from a collection of pigs owned by the household

Increases the collection pigs in proportion $(150 \mathrm{~kg})$ to the food/feed (maize, cassava, rice) surplus of the household at the end of each year

Increases the buffaloes collection of a number of buffaloes representing a multiple of $2 \times 10^{6}$ Vietnamese dong in the wallet if no buffalo in the household died over the past $4 \mathrm{yr}$

Adds new buffaloes to the collection buffaloes when conditions for newborn are fulfilled (1 calf every $2 \mathrm{yr}$ for female buffalo) 
managementBuffalo
Management of the buffaloes according to aStrategy with: aCondition. Buffaloes are kept in the house and fed with crop residues or natural vegetation is cut and carried (aStrategy $=1$ ). Buffaloes are sent to noncultivated cells belonging to the household (aStrategy $=2$ ). Buffaloes are sent to roam in the common forest $($ aStrategy $=3)$.

Farmer

ID

IDHouseHold

age

$\operatorname{sex}$
Integer

Integer

Integer

Symbol initialization

increaseAge
Farmer code, unique value for each person

Code of the household to which the farmer belongs

Age of the farmer

A symbol representing the sex of the farmer: male or female

Initializes the attributes of the agent

Increases the age of the agent at each time step

Buffalo

Integer

Integer

IDHouseHold

age

$\operatorname{sex}$

ID

Integer

Symbol initialization

increaseAge

movement

mortality

damageCrop
Buffalo code, unique value for each buffalo head

Code of the household to which the buffalo belongs

Age of the buffalo

A symbol representing the sex of the buffalo: male or female

Initializes the attributes of the agent

Increases the age of the agent at each time step

Moves buffaloes to cells in a collection aCollect according to a management strategy

Removes buffaloes from collection buffaloes when conditions for survival, i.e., adequate grazing area per buffalo, are not fulfilled

Reduces the regeneration speed of natural vegetation in the cell in which a buffalo is located and in surrounding cells 
Pig

IDHouseHold Integer Code of the household to which the pig belongs

initialization

Initializes the attributes of the agent

Cell

\begin{tabular}{|c|c|}
\hline state & Integer \\
\hline IDHouseHold & Integer \\
\hline age & Integer \\
\hline oldState & Integer \\
\hline yield & Integer \\
\hline remoteness & Integer \\
\hline suitablePaddy & Boolean \\
\hline suitableMaize & Boolean \\
\hline $\begin{array}{l}\text { suitableUpland- } \\
\text { Crop }\end{array}$ & Boolean \\
\hline soilType & Integer \\
\hline & \\
\hline & \\
\hline
\end{tabular}

regeneration

Code of the land use class

Code of the household to which the cell or plot belongs

Age of the environment, i.e., number of years under the current land-use type

Code of the land-use class preceding the current one

Yield of each crop according to the preceding land use, number of years of the current land use, soil type, etc. as indicated in the parameter interface

Distance from the residential areas is computed automatically in the remoteness layer

Variable indicating land suitability for paddy cultivation (yes or no)

Variable indicating land suitability for continuous maize cultivation (yes or no)

Variable indicating land suitability for upland crop cultivation: maize, soybean, cassava on sloping land (yes or no)

Code of the different soil types

Initializes the attributes of the cell

Increases the age of the environment at each time step

Regeneration of the natural vegetation 


\section{APPENDIX 2}

Fig. A2-1. Different views of the environment and the agents after 10 time steps in a village of Cho Don District. (A) Land use/land cover; (B) remoteness or distance to residential areas; (C) land ownership, i.e., all the cells of a particular color belong to the same agent, except for the yellow cells, which are not allocated; (D) soil types; (E) land suitable for terracing paddy fields in red, with access to water for irrigation; (E) land suitable for continuous maize cropping on the hillsides in red, flat land on soils derived from limestone.

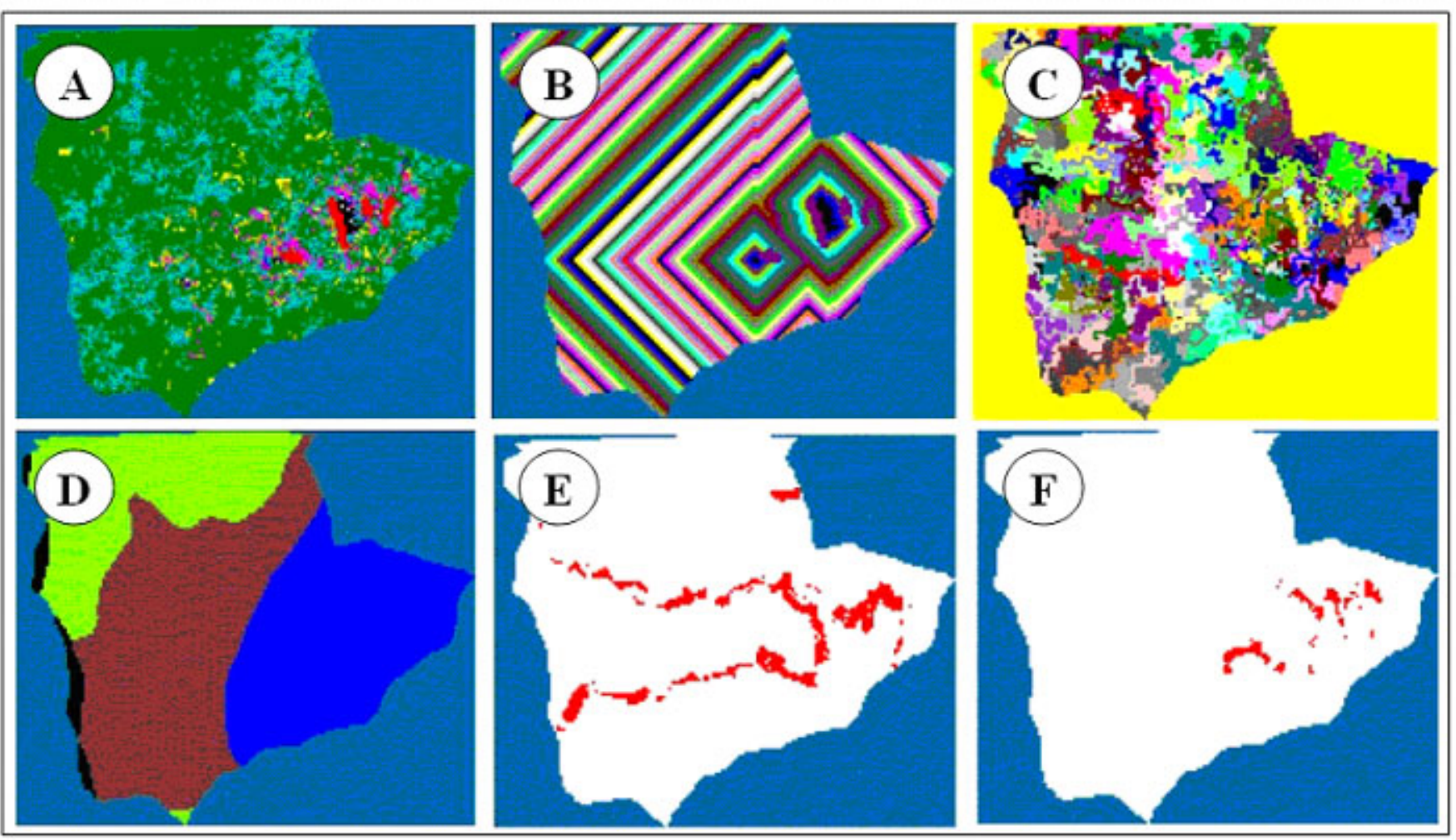


Fig. A2-2. Evolution of land use/land cover near Thon 2A village in Tan Lap commune at successive time steps of the simulation, with symbols of livestock agents overlaid on the grid.

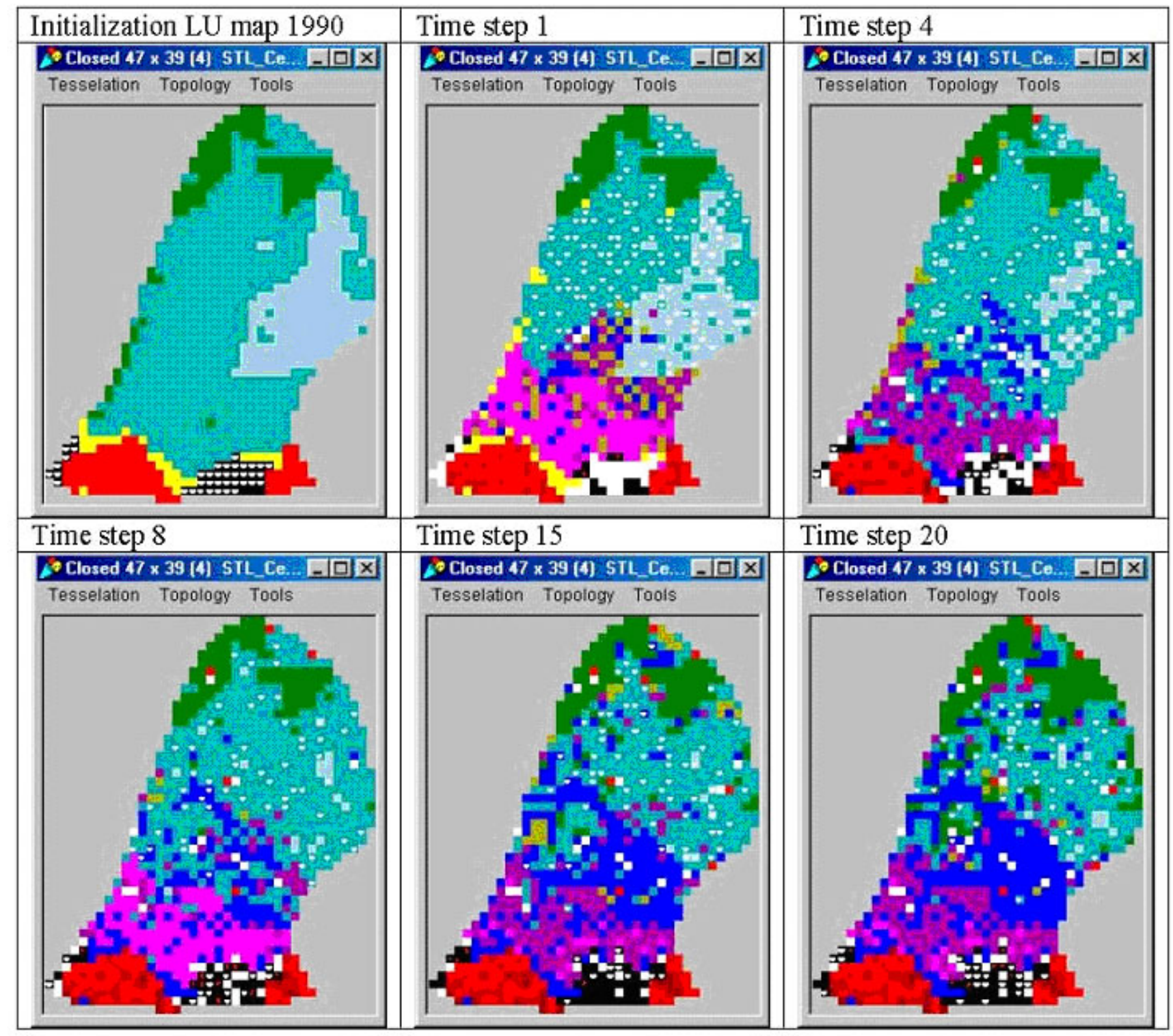

\begin{tabular}{|lll|}
\hline Legend & $\square$ Paddy 1 cycle & $\square$ Cassava \\
$\square$ Dense forest & $\square$ Paddy 1 cycle & $\square$ Cell with buffalo \\
$\square$ Open forest & $\square$ Paddy 1 cycle & $\square$ Cell with pigs \\
$\square$ Grass / shrub & $\square$ Maize & $\square$ Residence \\
Perennial trees & $\square$ Soybean & $\square$ Field hut / new house \\
\hline
\end{tabular}


Fig. A2-3. Graphics representing the changes in land use and evolution of livestock herd of the whole community during a simulation with SAMBA-GIS.

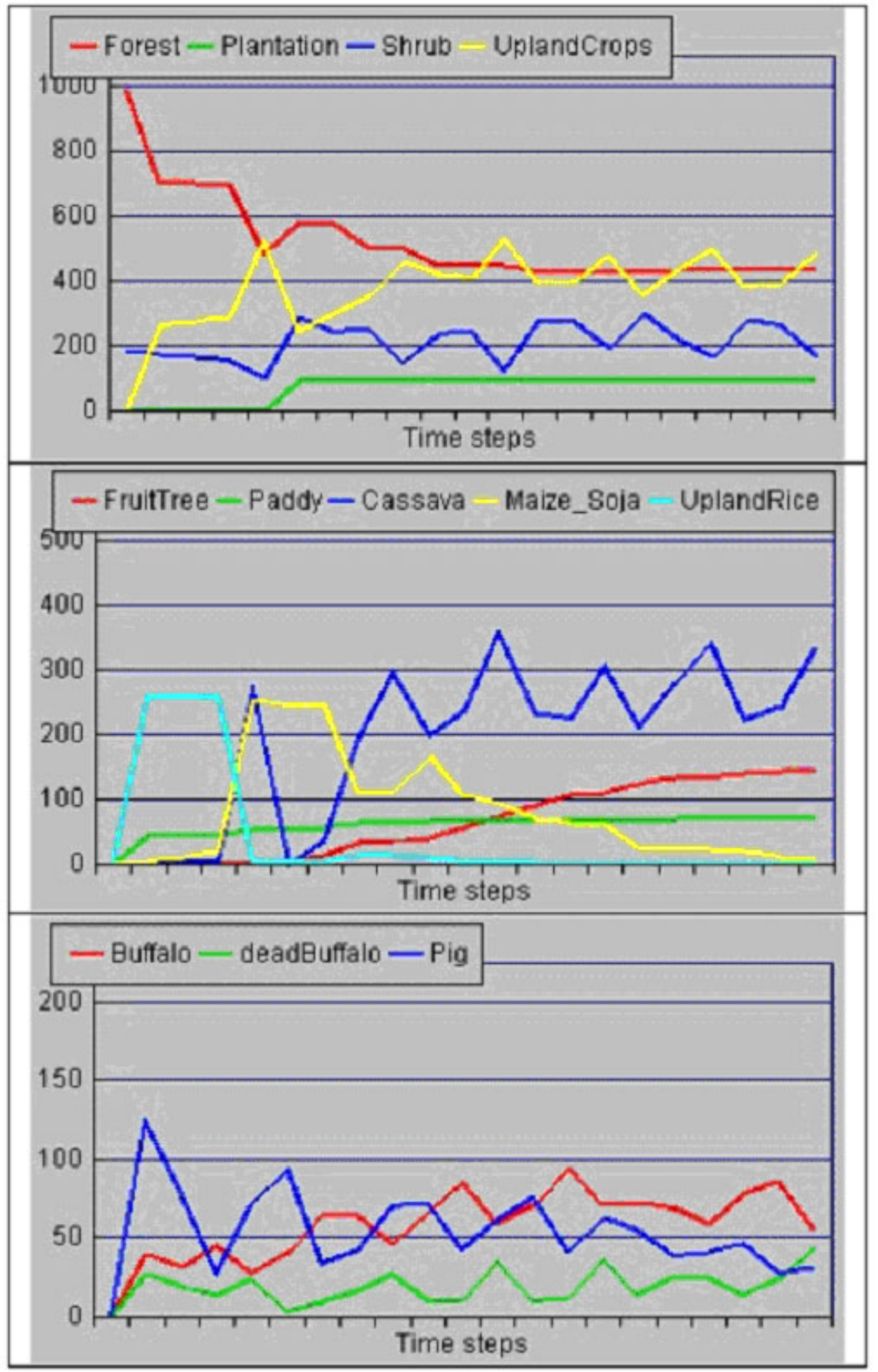

